\title{
A Precursory Signal of the Central Pacific El Niño Event: Eastern Pacific Cooling Mode
}

\section{Tao Lingjiang}

Fudan University

Duan Wansuo ( $\square$ duanws@lasg.iap.ac.cn )

LASG, Institute of Atmospheric Physics, Chinese Academy of Sciences

\section{Research Article}

Keywords: precursory signal, Central Pacific El Niño event, Eastern Pacific cooling mode, sea surface, temperature, experiments, regression models

Posted Date: November 3rd, 2021

DOI: https://doi.org/10.21203/rs.3.rs-992983/v1

License: (1) This work is licensed under a Creative Commons Attribution 4.0 International License. Read Full License 
${ }^{1}$ Department of Atmospheric and Oceanic Sciences \& Institute of Atmospheric Sciences, Fudan University, 
19 In recent decades, the tropical Pacific frequently experiences a new type of El Niño with 20 warming center in the central tropical Pacific (i.e., the CP-El Niño) with distinct global 21 climate effect to the traditional El Niño (i.e., EP-El Niño). Predicting the El Niño diversity is 22 still a huge challenge for climatologists partly due to the precursory signals of El Niño events 23 with different type is unclear. In the present study, a novel precursory signal that presents a 24 negative sea surface temperature anomaly in the eastern tropical Pacific (i.e., EP-cooling 25 mode) is revealed, which tends to evolve into a CP-El Niño event. The transition from the 26 EP-cooling mode to CP-El Niño is explained by the basin-scale air-sea coupling in the 27 tropical Pacific and teleconnections between the tropical and North Pacific. With the EP28 cooling mode as a predictor, the forecast skill for the CP-El Niño in hindcast experiments is 29 obviously improved by using regression models. The results in the present study are therefore 30 instructive for promoting a better understanding of El Niño diversity and predictability. 


\section{Introduction}

The El Niño-Southern Oscillation (ENSO) is recognized as one of the most prominent interannual variabilities in the climate system (Philander 1983) and has been extensively explored due to its profound global impacts [see the review by Wang (2019)]. After the 1990s, a new flavor of El Niño with the warming center in the central tropical Pacific (hereafter referred to as CP-El Niño), which is different from the conventional El Niño with a warming center in the eastern tropical Pacific (hereafter referred to as EP-El Niño), hoves into view of researchers [see the review by Timmermann et al. (2018)]. Though the CP-El Niño possesses a much smaller amplitude of sea surface temperature (SST) anomalies than the EP-El Niño, their climate effects are comparable (Ashok et al. 2007). Therefore, increasing efforts are focused on better understanding the dynamics of different El Niño events. The EP-El Niño event has been suggested as a basin-scale air-sea coupling phenomenon (Bjerknes 1969; Zebiak and Cane 1987), which can be well explained by the fluctuation of thermocline and charge-recharge theory (Jin 1997). The CP-El Niño event is more likely to be interpreted as resulting from the zonal advection feedback (Kug et al. 2009;

49 Yu and Kim 2010; Duan et al. 2014); in particular, it was observed to be associated with the local development of wind and thermocline anomalies, thus suggesting a local air-sea coupling phenomenon (Kao and Yu 2009).

Beyond looking at the dynamics of different types of El Niño formations, the identification of the precursory signals is also vital to understand and predict El Niño

54 diversities. Some studies have suggested that the precursory signals of El Niño events with different types originate from the extratropical Pacific (Ham et al. 2013; Ding et al. 2017; You and Furtado 2017; Wang et al. 2018; Wang et al. 2019a, b). For instance, a dipole structure of sea level pressure (SLP) variability over the North Pacific, known as the North 
Pacific Oscillation (NPO; Rogers 1981), has the ability to lead a CP-El Niño event (Yu and Kim 2011) through the "seasonal footprinting mechanism" (SFM) (Vimont et al. 2001, 2003a, b). Particularly, the NPO can impart a horseshoe SST footprint called the Victoria Mode (VM; Bond et al. 2003, Ding et al. 2015b) onto the North Pacific ocean and influence the SST anomaly (SSTA) in the central tropical Pacific. Thus, the CP-El Niño events occurred frequently in recent decades as the NPO turns into dominant North Pacific climate variability (Yeh et al. 2015). By contrast, the precursory signal of the EP-El Niño events is associated with the south Pacific, e.g., the Pacific-South American (PSA) pattern (Mo 2000) over the south Pacific that is found to have the potential to trigger an EP-warming event in the tropical Pacific (Ding et al. 2015a).

Since extratropical climate variability is largely modulated by tropical SST variability (Alexander et al. 2002; Yu and Kim 2011), it is therefore inferred that distinct precursors to two types of El Niño may exist in the tropical Pacific. Several studies have reported that a basin-scale deepened thermocline and positive SSTA in the eastern tropical Pacific are most favorable for the generation of EP-El Niño events after 12 months (Mu et al. 2014; Hu and Duan 2016). Capotondi and Sardeshmukh (2015) emphasized the two-season precursor of thermocline anomalies to the formation of El Niño types; specifically, a deeper thermocline in the central Pacific and a shallower thermocline in the eastern Pacific at a two-season leadtime tend to induce a CP-El Niño event, while a reverse thermocline tends to lead to an EP-El Niño. However, Yu and Kim (2010) focused on the evolution of the CP-El Niño and argued that the generation of CP-El Niño does not depend on the thermocline while its decay does. Obviously, the CP-El Niño precursory signal in the thermocline is still under debate. The dispute regarding to the precursor of the CP-El Niño come partly from the artificial 
and CP-El Niño events (Ashok et al. 2007; Kao and Yu 2009; Kug et al. 2009; Ren and Jin 2011; Sullivan et al. 2016), leading to varying outcomes for El Niño types. Thus, the different precursors of CP-El Niño in some studies is attributable to the definition of El Niño diversities that the authors adopted. To avoid this confusion, a consensus analysis is preferred to classify the El Niño type and then to explore the common precursory signal of CP-El Niño regardless the various definitions. In the present study, the CP-El Niño precursory signals in the tropical Pacific is re-examined and analyzed with observations and model simulations. Particularly, a novel CP-El Niño precursory signal, i.e., the SST cooling mode in the eastern tropical Pacific (hereafter referred to as the EP-cooling mode) is reported to serve an optimal condition for the onset of CP-El Niño. Then, hindcast experiments are conducted to confirm the validity of the EP-cooling mode as a precursory signal for improving SST predictions associated with CP-El Niño events.

The rest of the paper is organized as follows. Section 2 describes the data and methods that are used to explore the different precursory signals of the CP- and EP-El Niño. In Section 3, the EP-cooling mode as CP-El Niño precursor is investigated, followed by discussion in Section 4 on the involved dynamics of the transition from the EP-cooling mode to the CP-El Niño. In section 5, the effect of the previous SSTAs in the eastern tropical Pacific on the ENSO prediction. The paper will end with a summary and discussion in Section 6.

\section{Data and Methods}

\subsection{Data Sets}

In the present study, observational/reanalysis monthly data are adopted to explore the

103 precursory signal of El Niño events. The monthly SST data are from the Met Office Hadley

104 Centre Sea Ice and Sea Surface Temperature (HadISST) dataset (Rayner et al. 2003); the subsurface ocean data are from the Simple Ocean Data Assimilation (SODA, version 2.2.4) 
106 (Carton and Giese 2008); and the surface atmospheric and heat flux data are derived from the

107 Twentieth Century Reanalysis (20CR) (Compo et al. 2011). All these data are linearly pre-

108 detrended and analyzed during the period from January 1900 to December 2010, which is

109 when the time series of the relevant data overlap. Anomalies of each physical variable field

110 are obtained on an interannual scale by subtracting the climatological monthly mean from the

111 above data, where the climatology is the climatological annual cycle derived from the

112 corresponding variable data. In addition, the model data that are outputted from the

113 preindustrial simulations by the Climate Model Intercomparison Project version 5 (CMIP5)

114 are also adopted to examine the precursory signal of CP-El Niño events.

\section{$115 \quad 2.2$ The definition of El Niño events with different types}

116 The El Niño events in the present study are identified as those with a three-month mean

117 of the Niño 3.4 index (i.e., the averaged SSTAs over the Niño 3.4 region) greater than or 118 equal to $0.5^{\circ} \mathrm{C}$ that persist for at least five consecutive months. As mentioned in the

119 introduction, the definitions of El Niño diversity vary. Here, five methods are adopted to 120 identify the types of El Niño by defining CP and EP indices (Ashok et al. 2007; Kug et al. 121 2009; Sullivan et al. 2016; Ren and Jin 2011; Kao and Yu 2009). In Kug et al. (2009), a CP-

122 El Niño year is defined as the El Niño year when Niño4 index is greater than Niño3 index in 123 the peak phase, where the Niño3 index is referred as EP index (EPI) and the Niño4 index is 124 regarded as CP index (CPI). In Ashok et al. (2007), the CPI is indicated by CPI $=T_{1}-0.5$. $125\left(T_{2}+T_{3}\right)$, where $T_{1}$ is area-averaged SSTA over the central tropical Pacific $\left(165^{\circ} \mathrm{E} \sim 140^{\circ} \mathrm{W}\right.$, $\left.12610^{\circ} \mathrm{S} \sim 10^{\circ} \mathrm{N}\right) . T_{2}$ and $T_{3}$ are respectively those over the eastern $\left(110^{\circ} \mathrm{W} \sim 70^{\circ} \mathrm{W}, 15^{\circ} \mathrm{S} \sim 5^{\circ} \mathrm{N}\right)$ 127 and western tropical Pacific $\left(125^{\circ} \mathrm{E} \sim 145^{\circ} \mathrm{E}, 10^{\circ} \mathrm{S} 20^{\circ} \mathrm{N}\right)$. Ren and Jin (2011) proposed a 128 nonlinear indices based on the Niño3 and Niño4 indices as follows: 
$129\left\{\begin{array}{l}E P I=N i n o 3-\alpha \cdot N i n o 4 \\ C P I=N i n o 4-\alpha \cdot N i n o 3\end{array}\right.$, where $\alpha=\left\{\begin{array}{c}\frac{2}{5}, \quad \text { Nino3 } \cdot \text { Nino4 }>0 \\ 0, \quad \text { otherwise }\end{array}\right.$. Similarly, Sullivan et al.

130 (2016) use normalized Niño3 and Niño4 (denoted as Niño3n and Niño4n) to formulate CPI

131 and EPI, namely, EPI $=\operatorname{Nino3n}-0.5 \cdot \operatorname{Nino} 4 n, C P I=N i n o 4 n-0.5 \cdot N i n o 3 n$. From Kao

132 and $\mathrm{Yu}$ (2009), the CPI (EPI) is the principal component of leading mode in the tropical

133 Pacific that is filtered the linear effect of the SSTAs in the eastern (central) tropical Pacific.

134 According to above methods, we used their consensus results to determine the type of El

135 Niño. Then, a total of 17 CP-El Niño and 15 EP-El Niño events are obtained during the 136 period from January 1900 to December 2010 (see Table 1).

$137 \quad$ 2.3 Statistical Methods

138 To highlight the important role of the precursory signal in promoting the onset of CP-El

139 Niño, the climate variability unrelated to the precursor should be verified to have little impact

140 on the development of the CP-El Niño. In the present study, a filter technique is adopted to

141 obtain the climate variability that is unrelated to the CP-El Niño precursor. This filter

142 technique is described in Eq. (1), and the linear effect of $x(t)$ on $y(t)$ can be removed as

143 follows:

$$
y_{-x}(t)=y(t)-(\alpha+\beta \cdot x(t))
$$

where $y_{-x}(t)$ is the residual variability of $y(t)$ after removing the linear effect of $x(t)$ and $\alpha$ and $\beta$ are obtained from the regression analysis between $x(t)$ and $y(t)$. Evidently, the residual

147 variability $y_{-x}(t)$ is unrelated to $x(t)$, where if $x(t)$ is a precursor, then $y_{-x}(t)$ is the climate 148 variability that is part of $y(t)$ but unrelated to $x(t)$.

149 The significance of the correlation is determined using a two-tailed Student's test, which 150 involves the effective degree of freedom $N_{e}$ proposed by Bretherton et al. (1999). 


$$
N_{e}=N \frac{1-r_{x} r_{y}}{1+r_{x} r_{y}}
$$

152 where $r_{x}$ and $r_{y}$ are the autocorrelation of variables $x$ and $y$ with lag 1 , respectively, and $N$ is

153 the length of the variables. The composite analysis that confirms the result indicated by the 154 correlation analysis is also performed.

\section{Precursory signal of the CP-El Niño events}

To classify the EP- and CP-El Niño life cycles in the observation, we conduct a lagged correlation of the wintertime CP-El Niño index (CPI) and EP-El Niño index (EPI) with the SST and wind anomalies in the tropical Pacific (see Figures 1 and 2), where the EPI and CPI are obtained based on the definitions mentioned in section 2 . It is easily seen that the initial warming of both EP- and CP-El Niño events, in accordance with the previous studies (e.g., Wang et al. 2019; Yang et al. 2021), start from the western Pacific warming since the small perturbation of SST in the warm pool are easy to influence the atmosphere and trigger west

164 wind anomalies. Then, this western Pacific warming can be propagated eastward by the ocean current and amplified by the fluctuations of the thermocline. That is, the western Pacific warming tends to develop into an El Niño event via the zonal advection feedback and

167 thermocline feedback processes. However, both EP- and CP-El Niño events can start from 168 the WP warming, the WP warming therefore cannot act as an effective precursor to identify 169 the El Niño types.

170 In fact, much early precursory signals of EP- and CP-El Niño events can be identified 171 from the Figures 1 and 2. Specifically, the early precursor of EP-El Niño event is associated 172 with the basin-scale cooling event that could trigger western Pacific warming and subsequent 173 Bjerknes mode [also see Bjerknes (1969) and Yu and Fang (2018)]. As the warm water 
174 accumulates westward, the eastern Pacific of EP-El Niño is so charged that it leads to a 175 strong discharge. The positive SSTA starts to decay rapidly and evolves into a double-year 176 central Pacific cooling event again (Hu et al. 2014). Differed to the EP-El Niño, the early 177 precursory signal of CP-El Niño is significantly related to a localized cooling event by 2 178 years ahead, i.e., a negative SSTA mode in the eastern tropical Pacific (hereafter referred to 179 as the EP-cooling mode). What is worth noting is that the finding is robust for the different 180 methods classifying types of El Niño. Therefore, a hypothesis is that the EP-cooling mode 181 may be a precursory signal (at the two-year lead) of the CP-El Niño, which is different from 182 the initial warm signal with a one-year lead time in the western-central tropical Pacific for the 183 EP- and CP-El Niño.

184 To confirm the validity of the precursory EP-cooling mode of the CP-El Niño in identifying types of El Niño events in advance, we examine whether the tropical Pacific experienced an EP-cooling mode before each of the El Niño events. Here, the EP-cooling mode is defined as a negative and cooler SSTA in the eastern Pacific $\left(110^{\circ} \mathrm{W} \sim 80^{\circ} \mathrm{W}\right.$, $\left.5^{\circ} \mathrm{S} \sim 5^{\circ} \mathrm{N}\right)$ than the central tropical Pacific $\left(175^{\circ} \mathrm{W} \sim 110^{\circ} \mathrm{W}, 5^{\circ} \mathrm{S} \sim 5^{\circ} \mathrm{N}\right)$ from January-June. It

189 is found that the majority of $(88.2 \%)$ CP-El Niño events were evolved from the EP-cooling 190 mode at 1-2 years lead time during 1900-2010 (see Table 1). Moreover, 67\% of EP-El Niño events were unrelated to the previous EP-cooling mode. It is indicated that the EP-cooling mode is a reliable precursory signal for CP-El Niño. This information may provide important insights for classifying the type of upcoming El Niño event in advance.

Due to the limitation of the short period of the observation data, the model output from the CMIP5 experiments are analyzed as supplementary. Since current models still exhibit large biases in EP- and CP-El Niño simulations as well as their precursors (Taschetto et al. 
198 preceded by central Pacific cooling (CP-cooling) and EP-cooling modes to indicate whether a

199 CP- or EP-El Niño will occur. A heat center index (HCI) is employed to quantify the position

200 of the warming center of the SSTA as follows (Hu and Fedorov 2018):

201

$$
\mathrm{HCI}=\frac{\sum l \cdot T(l)}{\sum T(l)}
$$

where $l$ is the longitude within $160-90^{\circ} \mathrm{W}$ and $T$ is the averaged SSTA within $5^{\circ} \mathrm{S}$ to $5^{\circ} \mathrm{N}$.

Since the warming center of SSTA is only considered in the present study, $T(l)$ with negative

values is set to zero to avoid the illusory impact of a negative SSTA on the determination of HCI.

The changes in the HCI of the El Niño events from each model are displayed in Figure

3. It can be seen that 21 out of 26 models show that the location of the warming centers for the El Niño events originated from the EP-cooling mode are more west than those from the CP-cooling mode (Figure 3). It is indicated that the previous negative SSTAs in the eastern tropical Pacific (i.e., the EP-cooling mode) favor future central Pacific SST warming. These model results further confirm the fact derived from the observation that the EP-cooling mode

212 is a useful precursory signal of CP-El Niño-like events.

\section{Mechanism to the precursory signal EP-cooling mode transitioning to CP-EI Niño} event

The previous section has fully corroborated the fact that the EP-cooling mode is the

217 precursory signal of the CP-El Niño event, while the processes involved with such evolution 218 is unclear. Therefore, in this section, we will examine how the cooling signal evolve into to a

219 CP-El Niño event from the perspective of the air-sea interaction. 

bridged by the subtropical Pacific warming that is induced by basin-scale easterly wind anomalies. Figure 4 displays the air-sea evolution associated with the CPI proposed by Ashok et al. (2007) as an example (Note: the CP-El Niño related air-sea evolution is similar when using different CPIs). The EP-cooling mode imposing on the climatological ocean enhances the zonal gradient of the equatorial SST, thereby accelerating the Walker circulation. Thus, southeasterly wind anomalies prevail over the equatorial Pacific (Figure 4b), leading to anomalous mass transport towards the subtropical Pacific and western tropical Pacific. Infected by such V-shaped warming in the tropical subsurface, the tropical Pacific experiences a "Pacific meridional mode" (PMM; Chiang and Vimont 2004)-like air-sea coupling pattern that presents a dipole SSTA coupled with southwest wind anomalies in the eastern tropical Pacific (see Figure 4c). The positive SSTA of the PMM can be maintained and amplified through positive feedback known as the wind-evaporation-SST (WES) feedback (Xie and Philander 1994). Particularly, the anomalous westerly over the subtropical Pacific that acts to slack the trade wind tends to suppress evaporation and warm up the ocean, giving rise to the development of SSTA which will in turn feedback to the atmospheric and enhance the wind anomaly. The positive SSTA and anomalous westerly gradually invade into the central equatorial Pacific, leading to a strong zonal advection feedback, of which conditions are favorable for the formation of CP-El Niño events. Finally, the EP-cooling mode disappears and is replaced by a CP-El Niño-like event.

The EP-cooling mode can also influence the atmospheric state over the North Pacific, thus favoring the development of SSTAs in the central tropical Pacific through the oceanic path. To examine the relationship between the precursory state in the tropical Pacific ocean and the North Pacific atmosphere, a cross-correlation is performed between the SSTAs 
245 (meridionally averaged over $5^{\circ} \mathrm{S}-5^{\circ} \mathrm{N}$ ) along the equatorial Pacific in April-May-June (when 246 the precursory signal of the EP-cooling mode usually arises) and the SLP anomalies (zonally 247 averaged over $170^{\circ} \mathrm{W}-160^{\circ} \mathrm{W}$ ) over the North Pacific in February-March (when the NPO 248 peaks) in the next year. As shown in Figure 5a, the SSTAs in the eastern equatorial Pacific 249 (EP-SST) are significantly correlated with the SLP over the North Pacific, presenting a 250 negative correlation with the area north of $30^{\circ} \mathrm{N}$ and a positive correlation to the south. This means that the NPO is related to the previous negative EP-SST. However, since the EP-SST is directly link to the ENSO signals, one may wonder whether ENSO or EP-cooling mode can trigger the NPO event. To this end, the correlation is conducted between the SLP and the EPSST, where the latter is removed by the liner effect of the Niño3.4 indices. Figure $5 b$ clearly shows that the NPO is significantly related to the previous signals in the eastern tropical Pacific. That is, the EP-cooling mode has the potential to trigger a NPO-like atmospheric mode off the tropical Pacific through teleconnection mechanism, where the NPO can induce the occurrence of the CP-El Niño (Yu and Kim 2011; Pegion and Alexander 2013; Yeh et al. 2015).

We also conduct composites of the EP-cooling mode and its following air-sea states to verify the former mentioned possible mechanisms. Results are shown in Figures 6 and 7.

262 Consistent with the correlation analyses, the occurrence of the EP-cooling mode excites basin-scale east wind anomalies (Figures $6 \mathrm{a}$ and $7 \mathrm{~b}$ ), leading to the accumulation of ocean in

264 the western tropical and the transportation of warm water to the subtropical Pacific (Figures $2656 \mathrm{~b}$ and $6 \mathrm{~d}$, near $\left.10^{\circ} \mathrm{N}\right)$. Meanwhile, the EP-cooling mode can act on the SLP in the north 266 tropical Pacific in the spring of the next year and warm up the northeastern part of the north tropical Pacific as a VM-like footprint (Figure 7d). Such warming signal gradually invade into the central tropical Pacific leading to a CP-El Niño event (Figure 7f). Combined the 
former composite and correlation analyses, it shows that the transition from the EP-cooling mode to the CP-El Niño event is related to the basin-scale air-sea coupling in the tropical Pacific and its induced NPO in the north tropical Pacific.

In fact, not all NPOs can force the ocean to influence the central tropical Pacific (e.g., 2002 CP-El Niño event), while EP-cooling-induced NPOs do exert such influence. It is noted that the footprint over the ocean imprinted by the NPO, i.e., the VM, is an important interannual variability of the SST in the North Pacific that transmits the information of the North Pacific to the tropical Pacific. To elucidate the role of the VM that is related to the EPcooling mode, the lag correlations with the VM index (VMI; i.e., the second principle of SSTA in the north tropical Pacific) and the VMI unrelated to the EP-cooling mode (calculated by Eq. (1)) are calculated with the SST, surface wind, latent heat flux (LHF) and subsurface temperature anomalies (see Figure 3). As shown in Figure 8a, the VM is overlaid by basin-scale cyclone anomalies and possesses a positive SSTA in the North Pacific and a negative SSTA in the Northwest Pacific, which is consistent with the result of Ding et al. (2015b). The south band of the VM with the positive SSTA interacts with the corresponding anomalous southwesterly and tends to span southwestward, finally forcing the warming SST to invade the tropical Pacific through WES feedback, as indicated by the strong positive correlation between the VMI and LHF in the subtropical Pacific (see Figure 8c). Then, this warming SST is further forced by the VM-related equatorial wind anomaly and gradually yields CP-El Niño (Figure 8e). When removing the linear effect of the EP-cooling mode, the structure of the VM changes and the $\mathrm{CP}$ warming event does not occur (Figures $8 \mathrm{~b}, 8 \mathrm{~d}$ and 8f). Specifically, the correlation of the VM to the SSTA in the Northwest Pacific is weaker when the linear effect of the EP-cooling mode is filtered, indicating that the zonal gradient of 
293 decrease in westerly anomalies over the central North Pacific. Thus, as reflected in Figures 8d 294 and 8f, the strength of the WES feedback that maintains the development of the SSTA is 295 largely weakened as the ocean obtains less heat flux. In a weak WES feedback system, the 296 positive SSTA of the VM and relevant westerly anomalies that tend to extend into the central 297 equatorial Pacific are delayed. In this situation, there is almost no warming signal along the 298 equatorial Pacific in fall (Figure 8f) and the CP-El Niño event fails to take shape.

299 For comparison, the composites of EP-cooling related and unrelated VM are

300 implemented, which are shown in Figures 9 and 10, respectively. In this study, the VM 301 events are defined as when the VMI is larger than the half of its standard deviation during 302 FMA. The composite VM events that are associated with the previous EP-cooling mode 303 exhibit significant positive SSTAs and west wind anomalies in the north tropical Pacific 304 (Figure 9c). This kind of VM acts to warm up the central tropical Pacific at the end year of 305 VM (Figure 9d). In contrast, the composite VM events without the previous EP-cooling mode possess much weaker SSTA than the EP-cooling mode related VM events (Figures 9c and 10c). Hence, such weak VM is not strong enough to influence the central tropical Pacific and offset the tropical cooling signal. From the above, it is known that the EP-cooling mode is an important preceding factor to enhance the linkage between the VM and CP-El Niño events.

\subsection{Why a CP-cooling mode cannot lead to a CP-El Niño?}

311 Since the EP-cooling mode can evolve into a CP-El Niño event through tropical air-sea

312 coupling and teleconnection between the tropical and North Pacific, it naturally leads us to 313 question why a CP-cooling-like SSTA pattern does not produce such an effect.

According to the lag-correlation analysis (Figure 5), the lagged negative SLP anomalies

315 in the high latitudes tend to shift equatorward in response to the movement of the equatorial 316 SSTA from the eastern Pacific to the western Pacific. Hence, the negative SSTA in the 
317 central tropical Pacific is unable to trigger a NPO but favors the formation of a negative 318 Aleutian low. When we filter the effect of the EP-SST on the Niño3.4, we find the residual 319 Niño3.4 indices still present significant correlations to the SLP anomalies over the North 320 Pacific (Figure 5c). To better describe the distinct effect of EP-cooling and CP-cooling on the

321 North Pacific, the composites of the air-sea evolution induced by the CP-cooling and EP-

322 cooling modes are conducted and displayed in Figure 7. The CP-cooling triggered 323 atmospheric variability is significantly differed to that induced by the EP-cooling. For the CP-cooling mode, the central tropical Pacific cooling cooperated with the anticyclone flow over the North Pacific (i.e., negative Aleutian low mode) persist for one year (see Figures 7a and 7c). Without the blessing of the positive SSTAs in the eastern subtropical Pacific, the CP-El Niño events hardly occur (see Figure 7e).

The response of tropical wind anomalies to the CP-cooling is also different from that to the EP-cooling mode. The CP-cooling tends to promote anomalous divergence of surface wind in the central tropical Pacific (Figure 7a). Then, the CP-cooling-induced westerly anomalies in turn lead to ocean transport in the eastern Pacific converging to the equator, thus triggering the upwelling Rossby wave off the eastern equatorial Pacific (Figure 11a). This kind of cooling wave transmits westward and acts to maintain the negative SSTA in the central Pacific. Therefore, a CP-cooling event (i.e., CP-La Niña) usually persists to the next year (Hu et al. 2014) and then disappears (Figure 7e). Although the upwelling Rossby wave is also found in the EP-cooling case, this wave is delayed compared with the CP-cooling case as it is a kind of reflected Kelvin wave and a part of the wave energy is dissipated (Figure

338 11b). Thus, the cooling wave has little effect on the subtropical Pacific that is occupied by anomalously warm water. Above all, the CP-cooling mode does not favor a transition to a CP-El Niño event while the EP-cooling mode does. 
342 5. Hindcast experiments of ENSO with the SSTAs in the eastern tropical Pacific as a predictor

344 The above results have shown that the EP-cooling mode can serve as a useful precursory 345 signal of CP-El Niño events rather than EP-El Niño events, which may indicate that the 346 leading SSTAs in the eastern tropical Pacific are a useful predictor to improve the ENSO 347 prediction as well as the CP-El Niño predictions. To confirm this inference, a twin experiment regarding the regression-based hindcast is carried out. Previous studies (e.g.,

349 Fang and Mu 2018; Lai et al. 2018) have documented that wind and heat content indices are 350 useful predictors of ENSO events and constructed a linear regression air-sea coupling model 351 as in Eq. (4) for ENSO predictions.

$$
\text { Model 1: } \text { Nino }^{m}=\alpha \cdot \mathrm{ZW}^{M A M}+\beta \cdot \mathrm{HC}^{M A M}+\varepsilon \text {. }
$$

where $N_{i n o}{ }^{m}$ is the predicted Niño index (i.e., Niño3, Niño4, or Niño3.4 index) in month $m$, $\mathrm{ZW}^{M A M}$ and $\mathrm{HC}^{M A M}$ represent the springtime (i.e., March-April-May) zonal wind anomaly over the western tropical Pacific (averaged over the region $150^{\circ} \mathrm{E}-160^{\circ} \mathrm{W}, 10^{\circ} \mathrm{S}-10^{\circ} \mathrm{N}$ ) and equatorial thermocline fluctuation (defined as a depth of $20^{\circ} \mathrm{C}$ sea water temperature averaged in region $\left.120^{\circ} \mathrm{E}-80^{\circ} \mathrm{W}, 2^{\circ} \mathrm{S}-2^{\circ} \mathrm{N}\right)$, respectively. The relevant coefficients $\alpha, \beta$ and $\varepsilon$ are optimally obtained by training Model-1 from 1960-2010. Now, we include the leading SST signal of the eastern tropical Pacific in Model 1 with training from 1960-2010 and 360 formulate Model-2 as shown in Eq. (5).

$$
\text { Model 2: } \text { Nino }^{m}=\alpha \cdot \mathrm{ZW}^{M A M}+\beta \cdot \mathrm{HC}^{M A M}+\gamma \cdot \mathrm{EP}^{\text {prev }}+\varepsilon \text {, }
$$


where EP ${ }^{p r e v}$ is the leading SSTA (defined as the SSTA averaged over the region $110^{\circ} \mathrm{W}-$ $70^{\circ} \mathrm{W}, 5^{\circ} \mathrm{S}-5^{\circ} \mathrm{N}$ during the last year). These predictor (i.e., $\mathrm{ZW}^{M A M}, \mathrm{HC}^{M A M}$, and $\mathrm{EP}^{\text {prev }}$ ) are independent of each other, with correlations less than 0.2 at $99 \%$ confidence.

Note that the formulated Model 1 is demonstrated to possess high skills in ENSO predictions. Here, a comparison between Models 1 and 2 shows that the leading SST signal of the eastern tropical Pacific can further improve the prediction skill of the SSTA in the central tropical Pacific, as indicated by the correlation of the wintertime Niño4 index increasing from 0.65 to 0.72 (see Figures $12 \mathrm{~b}$ and $12 \mathrm{e}$ ). For the Niño3 index, the correlation only increases from 0.76 to 0.77 (see Figures $1 \mathrm{a}$ and $12 \mathrm{~d}$ ). In contrast, the prediction skills towards the CPI is increased by nearly $25 \%$ from 0.43 to 0.45 . Evidently, the leading SST signal in the eastern tropical Pacific is useful for improving the ENSO prediction skill, especially for the CP-El Niño events.

The effect role of previous EP-signal in ENSO predictions holds in the cross-validation experiments. We firstly train the models using the data from the period 1960-1985 and predict the SSTAs during 1985-2010 for validation. Then, models trained using the data from 1985-2010 is used to predict the SSTA during 1960-1985. The prediction skills are indicated in Figure 13. Clearly, the Model 2 shows better performance than the Model 1 in ENSO predictions during either the training periods or the predication periods, especially for the CPI predictions. The cross-validation experiment sheds light on the important role of the leading EP-SST in the prediction of SSTA in the central tropical Pacific as well as the prediction of

382 CP-El Niño events.

\section{Conclusions and Discussion}


The CP-El Niño, exerting a different global climate effect than the traditional type of El

386 Niño, occurs frequently since the twelve first century. Besides the strength of El Niño,

387 predicting its horizontal pattern is also important. While due to the limitation of climate 388 models, most models lose skills in predicting the El Niño type after one season (e.g., Hendon 389 et al. 2009; Tao et al. 2020), especially for the CP-El Niño prediction. One of main reasons is 390 the lack the knowledge of the origination of EP- and CP-El Niño and their evolution mechanism.

To this end, the present study explores CP-El Niño precursory signals using the reanalysis data. It is found that an EP-cooling mode that presents a negative SSTA in the eastern tropical Pacific is much more likely to induce the onset of CP-El Niño events one year later. By observing previous condition of the El Niño events whether are the EP-cooling type or not in the tropical Pacific, the types of El Niño are well pre-identified. It is therefore confirmed that the EP-cooling mode in the tropical Pacific can be served as a reliable predictor for distinguishing the type of El Niño that will occur. Particularly, a linear regression model is constructed to illustrate the validity of the precursory EP-cooling mode in

400 improving CP-El Niño predictions. Physically, the transition from the EP-cooling mode to a 401 CP-El Niño is shown to be related to the basin-scale easterly wind anomalies in the tropical 402 Pacific induced by the EP-cooling mode and the NPO-like atmospheric anomalies in the 403 North Pacific. The occurrence of the EP-cooling mode enhances the Walker circulation so 404 that a basin-scale easterly wind anomaly is triggered to transport warm water poleward and 405 westward. Then, the EP-cooling mode tends to induce a PMM-like SSTA pattern that has the 406 potential to generate the CP-El Niño event under the condition of strong zonal advection 407 feedback in the central western tropical Pacific. Moreover, the EP-cooling mode tends to 
trigger the NPO-like atmospheric anomaly, which forces the Pacific ocean to warm up the central tropical Pacific by the oceanic path of the VM.

An emphasis is that when filtering the effect of the EP-cooling mode, the residual VM can hardly induce a CP-El Niño but tends to generate a weak EP-El Niño event due to the weak WES feedback. The EP-cooling mode is clearly a better precursory signal of the CP-El

413 Niño than the VM or NPO because the latter two can also cause an EP-El Niño event (Ding et al. 2017). What is noteworthy is that the CP-El Niño is more and more related to the precursory EP-cooling mode in recent decades. As show in Figure 14, the connection between the previous EP-signal and the SSTA in the central tropical Pacific is lowest during 1930-1960. While, in recent decades, the SSTA in the central tropical Pacific is significantly correlated to the previous EP-signal, where the correlation is up to -0.6. Thus, a more attention is suggested to be payed to the EP-cooling mode so as to improve the El Niño diversity prediction in the situation of the global warming, especially considering the frequent occurrences of CP-El Niño.

What favors for the EP-cooling mode is not concerned here but of interest still. According to previous studies, the frequent occurrence of CP-El Niño events is associated with a climatological La Niña-like background and a climatological shallower thermocline of the tropical Pacific (Choi et al. 2011) due to the strong equatorial trade wind and crossequatorial wind over the eastern Pacific (Hu and Fedorov 2018). These climatological states may provide a favorable background for the occurrence of the EP-cooling mode. Besides, stochastic winds, such as synoptic-scale surface easterly wind surges, also play a role in the formulation of EP-cooling events (Chiodi and Harrison 2015), which may provide another 430 possible source of EP-cooling mode. In any case, longer observation datasets and more numerical experiments are still needed to verify the precursory EP-cooling mode and to 
432 explore its origination in future studies. Despite the various horizontal type of El Niño, the

433 diversities in the strength and duration period of El Niño are equally important to be profound

434 studied as well as their specific precursors. These researches including the current study are

435 expected to be helpful for having insights into the variability of short-term climate and then

436 to promote the prediction levels.

437

438

439

Acknowledgments.

440 This work was supported by the National Natural Science Foundation of China (Grant 441 Nos. 41930971, 41690124 and 41690120). The authors appreciate the Climate Model 442 Intercomparison Project (CMIP) that provides the model output freely (downloaded from $443 \quad$ https://esgf-node.llnl.gov/search/cmip5/)

Data availability statement

446 The monthly SST data from the Met Office Hadley Centre Sea Ice and Sea Surface

447 Temperature (HadISST) dataset were obtained at the website http://www.metoffice.gov.uk/ 448 hadobs/hadisst/data/download.html (Rayner et al. 2003); the subsurface ocean data are 449 obtained from the Simple Ocean Data Assimilation (SODA, version 2.2.4) (Carton and Giese 450 2008; http://apdrc.soest.hawaii.edu/datadoc/soda_2.2.4.php); and the surface atmospheric and 451 heat flux data are derived from the Twentieth Century Reanalysis (20CR) (Compo et al. 452 2011; downloaded from 453 http://iridl.ldeo.columbia.edu/SOURCES/.NOAA/.ESRL/.PSD/.rean20thcent/). The Climate 
454 Model Intercomparison Project (CMIP) are downloaded from https://esgf-

455 node.llnl.gov/search/cmip5/)

456

457 
460 Alexander, M. A., I. Blade, M. Newman, J. R. Lanzante, N. C. Lau, and J. D. Scott (2002), 461 The atmospheric bridge: The influence of ENSO teleconnections on air-sea interaction over the global oceans, J Climate, 15(16), 2205-2231.

Ashok, K., S. K. Behera, S. A. Rao, H. Y. Weng, and T. Yamagata (2007), El Niño Modoki and its possible teleconnection, J Geophys Res-Oceans, 112.

Bjerknes, J. (1969), Atmospheric Teleconnections from Equatorial Pacific, Mon Weather Rev, 466 97(3).

Bond N. A., J. E. Overland, M. Spillane, and P. Stabeno(2003) Recent shifts in the state of the North Pacific. Geophys Res Lett, 30. https://doi.org/10.1029/2003GL018597

Bretherton, C. S., M. Widmann, V. P. Dymnikov, J. M. Wallace, and I. Blade (1999), The effective number of spatial degrees of freedom of a time-varying field, J Climate, 12(7), 1990-2009.

Capotondi, A., and P. D. Sardeshmukh (2015), Optimal precursors of different types of ENSO events, Geophysical Research Letters, 42(22), 9952-9960.

Carton, J. A., and B. S. Giese (2008), A reanalysis of ocean climate using Simple Ocean Data Assimilation (SODA), Mon Weather Rev, 136(8), 2999-3017.

Chiang, J. C. H. and D. J. Vimont (2004), Analogous Pacific and Atlantic meridional modes of tropical atmosphere-ocean variability. J Climate, 17(21): 4143-4158. Onset of La Nina Events." Journal of Climate 28(2): 776-792. 
480 Choi, J., et al. (2011). "The role of mean state on changes in El Nio's flavor." Climate Dynamics 37(5-6): 1205-1215.

482

483

484

485

486

487

488

489

490

491

492

493

494

495

496

497

498

499

500

501

502

503

Compo, G. P., et al. (2011), The Twentieth Century Reanalysis Project, Q J Roy Meteor Soc, 137(654), 1-28.

Ding, R. Q., J. P. Li, and Y. H. Tseng (2015a), The impact of South Pacific extratropical forcing on ENSO and comparisons with the North Pacific, Clim Dynam, 44(7-8), 20172034.

Ding, R. Q., J. P. Li, Y. H. Tseng, C. Sun, and Y. P. Guo (2015b), The Victoria mode in the North Pacific linking extratropical sea level pressure variations to ENSO, J Geophys Res-Atmos, 120(1), 27-45.

Ding, R. Q., J. P. Li, Y. H. Tseng, C. Sun, and F. Zheng (2017), Linking a sea level pressure anomaly dipole over North America to the central Pacific El Niño, Clim Dynam, 49(4), 1321-1339.

Duan, W. S., B. Tian, and H. Xu (2014), Simulations of two types of El Niño events by an optimal forcing vector approach, Clim Dynam, 43(5-6), 1677-1692.

Fang, X. H. and M. Mu (2018), Both air-sea components are crucial for El Niño forecast from boreal spring, Scientific Reports, 8(1). https://doi.org/10.1038/s41598-018-28964-z

Ham, Y. G., J. S. Kug, and J. Y. Park (2013), Two distinct roles of Atlantic SSTs in ENSO variability: North Tropical Atlantic SST and Atlantic Niño, Geophysical Research Letters, 40(15), 4012-4017.

Hendon, H. H., E. Lim, G. M. Wang, O. Alves, and D. Hudson (2009) Prospects for predicting two flavors of El Niño. Geophys Res Lett. https:// doi.org/10.1029/2009g1040100

Hu, J. Y., and W. S. Duan (2016), Relationship between optimal precursory disturbances and 
optimally growing initial errors associated with ENSO events: Implications to target observations for ENSO prediction, J Geophys Res-Oceans, 121(5), 2901-2917.

Hu, S. N., and A. V. Fedorov (2018), Cross-equatorial winds control El Niño diversity and change, Nat Clim Change, 8(9), 798-+.

Hu, Z. Z., A. Kumar, Y. Xue, and B. Jha (2014), Why were some La Ninas followed by another La Nina?, Clim Dynam, 42(3-4), 1029-1042.

Jin, F. F. (1997), An equatorial ocean recharge paradigm for ENSO .1. Conceptual model, $J$ Atmos Sci, 54(7), 811-829.

Kao, H. Y., and J. Y. Yu (2009), Contrasting Eastern-Pacific and Central-Pacific Types of ENSO, J Climate, 22(3), 615-632.

Kim, S. T., J. Y. Yu, A. Kumar, and H. Wang (2012), Examination of the Two Types of ENSO in the NCEP CFS Model and Its Extratropical Associations, Mon Weather Rev, 140(6), 1908-1923.

Kug, J. S., F. F. Jin, and S. I. An (2009), Two Types of El Niño Events: Cold Tongue El Niño and Warm Pool El Niño, J Climate, 22(6), 1499-1515.

Lai, A. W. C., et al. (2018). "ENSO Forecasts near the Spring Predictability Barrier and Possible Reasons for the Recently Reduced Predictability." Journal of Climate 31(2):

Mo, K. C. (2000), Relationships between low-frequency variability in the Southern Hemisphere and sea surface temperature anomalies, J Climate, 13(20), 3599-3610.

Mu, M., Y. S. Yu, H. Xu, and T. T. Gong (2014), Similarities between optimal precursors for ENSO events and optimally growing initial errors in El Niño predictions, Theor Appl Climatol, 115(3-4), 461-469. 

simulation and impact on ENSO prediction. Clm Dynam, 2013, 41(5-6):1671-1683.

Philander, S. G. H. (1983), El-Niño Southern Oscillation Phenomena, Nature, 302(5906), 295-301.

Rayner, N. A., D. E. Parker, E. B. Horton, C. K. Folland, L. V. Alexander, D. P. Rowell, E. C. Kent, and A. Kaplan (2003), Global analyses of sea surface temperature, sea ice, and night marine air temperature since the late nineteenth century, $J$ Geophys Res-Atmos, 108(D14). https://doi.org/10.1029/2002JD002670

Ren, H. L., and F. F. Jin (2011), Niño indices for two types of ENSO. Geophys. Res. Lett. 38, L04704.

Rogers, J. C. (1981), The north Pacific oscillation, Journal of Climatology, 1(1), 39-57.

Sullivan A., J. J. Luo, A. C. Hirst, et al (2016), Robust contribution of decadal anomalies to the frequency of central-Pacific El Niño. Scientific Reports, 6(1):38540.

Taschetto, A. S., A. Sen Gupta, N. C. Jourdain, A. Santoso, C. C. Ummenhofer, .and. M. H. England MH (2014), Cold tongue and warm pool ENSO events in CMIP5: mean state

Tao, L. J., W. S. Duan, and S. Vannitsem (2020). Improving the forecasts of El Niño diversity: A nonlinear forcing singular vector approach. Clim Dynm, 55: 739-754. DOI: $10.1007 / \mathrm{s} 00382-020-05292-5$

Timmermann, A., et al. (2018), El Niño-Southern Oscillation complexity, Nature, 559(7715), 535-545.

549 Vimont, D. J., D. S. Battisti, and A. C. Hirst (2001), Footprinting: A seasonal connection between the tropics and mid-latitudes, Geophysical Research Letters, 28(20), 39233926.

552 Vimont, D. J., J. M. Wallace, and D. S. Battisti (2003a), The seasonal footprinting mechanism 

in the Pacific: Implications for ENSO, J Climate, 16(16), 2668-2675.

554 Vimont, D. J., D. S. Battisti, and A. C. Hirst (2003b), The seasonal footprinting mechanism in the CSIRO general circulation models, J Climate, 16(16), 2653-2667.

Wang B., X. Luo, Y. M. Yang, W. Y. Sun, M. A. Cane, W. J. Cai, S. W. Yeh, and J. Liu (2019). Historical change of El Niño properties sheds light on future changes of extreme El Niño, PNAS, 116 (45) 22512-22517; DOI: 10.1073/pnas.1911130116

Wang C. (2019). Three-ocean interactions and climate variability: a review and perspective(J). Climate Dynamics, 53, 5119-5136.

Wang, X., W. Tan, and C. Wang. (2018) A new index for identifying different types of El Niño Modoki events. Clim Dyn, 50: 2753-2765. https://doi.org/10.1007/s00382-017-

Wang X., M. Y. Chen, C. Z. Wang, et al. (2019a). Evaluation of performance of CMIP5 models in simulating the North Pacific Oscillation and El Niño Modoki. Clim Dyn, 52(3-4): 1383-94.

Wang X., C. Guan, R. X. Huang, W. Tan, and L. Wang. (2019b). The roles of tropical and subtropical wind stress anomalies in the el niño modoki onset. Clim Dyn, 52: 6585-

Xie, S. P., \& Philander, S. G. H. (1994). A coupled ocean-atmosphere model of relevance to 571 the ITCZ in the eastern Pacific. Tellus A, 46(4), 340-350. https://doi.org/10.3402/tellusa.v46i4.15484 ENSO related precipitation changes in the mid-latitudes. Nat Commun 12, 1495. https://doi.org/10.1038/s41467-021-21787-z 
North Pacific Climate Variability and the Central Pacific El Niño, J Climate, 28(2), 663-

578 677.

579

You, Y. J., and J. C. Furtado (2017), The role of South Pacific atmospheric variability in the

580 development of different types of ENSO, Geophysical Research Letters, 44(14), 74387446.

582

Yu, J. Y., and S. T. Kim (2010), Three evolution patterns of Central-Pacific El Niño, Geophysical Research Letters, 37. https://doi.org/ 10.1029/2010GL042810

Yu, J. Y., and S. T. Kim (2011), Relationships between Extratropical Sea Level Pressure Variations and the Central Pacific and Eastern Pacific Types of ENSO, J Climate, 24(3), 708-720.

Yu, J. Y., and S. W. Fang (2018), The Distinct Contributions of the Seasonal Footprinting and Charged-Discharged Mechanisms to ENSO Complexity, Geophysical Research Letters, 45, 6611-6618.

590 Zebiak, S. E., and M. A. Cane (1987), A Model El-Niño Southern Oscillation, Mon Weather Rev, 115(10), 2262-2278. 
Table 1 EP- and CP-El Niño events from 1900-2010 and their precursors. The types of El

596 Niño are determined according to the consensus among El Niño types identified by Ashok et 597 al. (2007), Ren and Jin (2011) and Kao and Yu (2009) according to their proposed El Niño 598 type definitions. "Y" denotes yes if the tropical Pacific has experienced an EP-cooling-like 599 mode preceding a CP type or a non-EP-cooling mode preceding an EP-El Niño event; 600 otherwise, "N" is indicated. And "*”" indicates that the EP-cooling mode occurs during the 601 later winter in the year (-1) and spring in the year (0) of El Niño. It can be found that 15 out 602 of 17 CP-El Niño events are denoted by "Y", indicating that these CP-El Niño events have an 603 EP-cooling precursory signal, which indicates that the majority of the CP-El Niño events 604 evolved from the EP-cooling mode.

\begin{tabular}{llllll}
\hline Year & Type & $\begin{array}{l}\text { EP-cooling } \\
\text { precursor }\end{array}$ & Year & Type & $\begin{array}{l}\text { EP-cooling } \\
\text { precursor }\end{array}$ \\
\hline 1902 & CP & Y & 1965 & CP & Y \\
1904 & CP & Y & 1968 & CP & Y \\
1905 & EP & Y & 1969 & EP & N \\
1911 & EP & Y & 1972 & EP & Y \\
1913 & EP & Y & 1976 & EP & Y \\
1914 & CP & Y & 1977 & CP & Y* \\
1918 & EP & Y & 1982 & EP & N \\
1923 & CP & Y & 1986 & EP & N \\
1925 & CP & Y & 1987 & CP & Y \\
1930 & EP & Y & 1991 & CP & Y \\
1939 & EP & N & 1994 & CP & Y* \\
1940 & CP & N & 1997 & EP & N \\
1941 & EP & Y & 2002 & CP & Y \\
1951 & EP & Y & 2004 & CP & Y \\
1957 & CP & Y* & 2006 & EP & Y \\
1963 & CP & Y & 2009 & CP & N \\
\hline
\end{tabular}

605 
(a) Nino

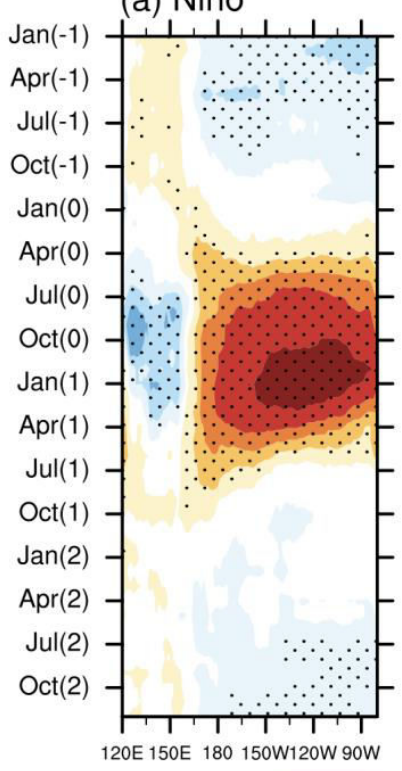

(b) Sullivan

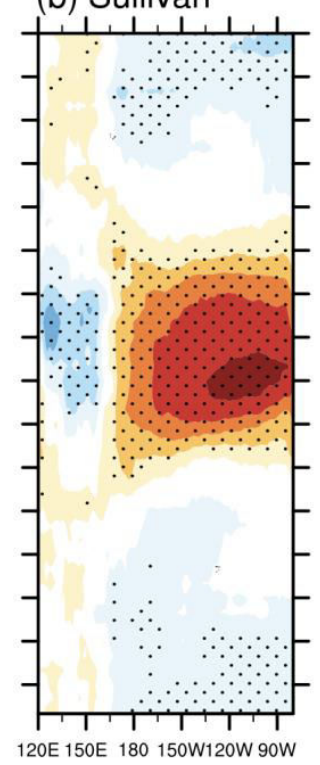

(c) RenJin

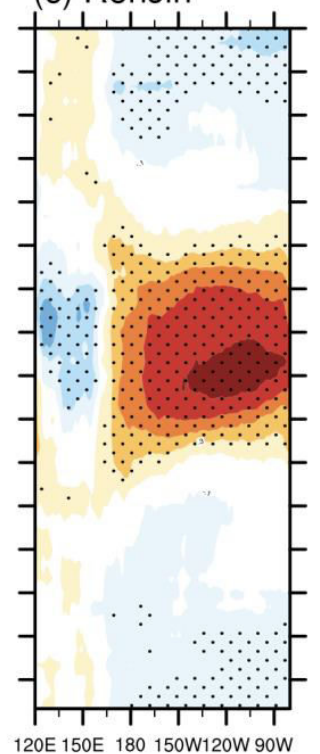

(d) KaoYu

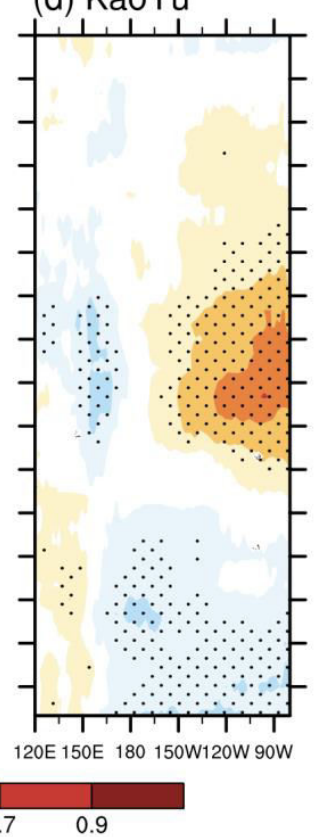

608 Figure 1 Correlations between the equatorial SSTA and wintertime (December-January-

609 February) EP-El Niño indices (EPIs) that are derived through the approaches proposed by (a)

610 Kug et al. (2009), (b) Sullivan et al. (2016), (c) Ren and Jin (2011) and (d) Kao and Yu

611 (2007). The correlations above 95\% confidence are dotted.

612

613 
(a) Nino

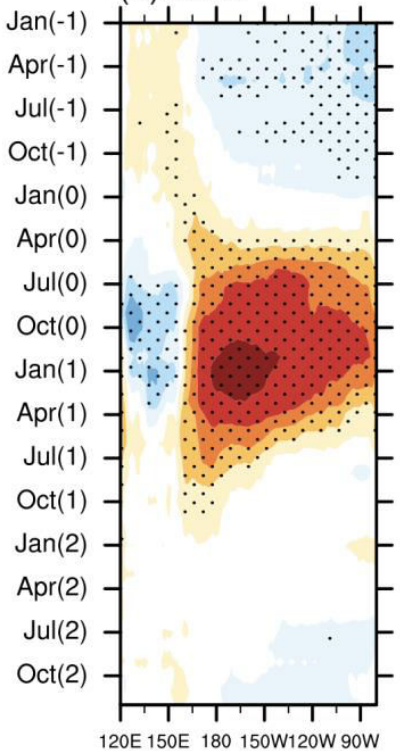

(b) Sullivan

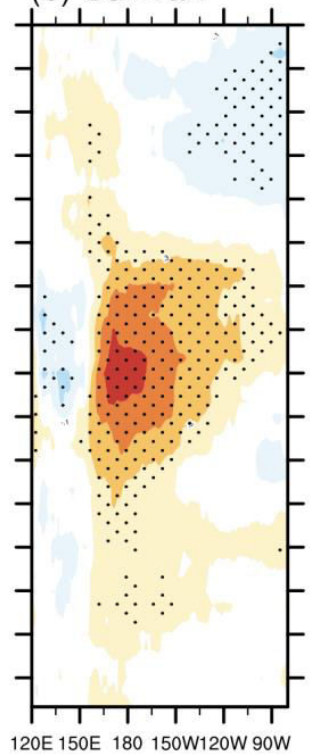

(c) RenJin

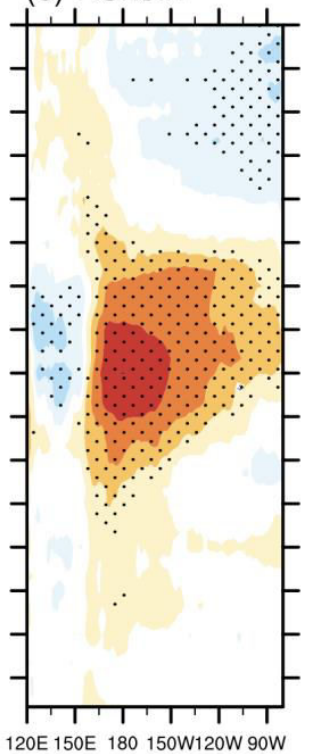

(d) KaoYu

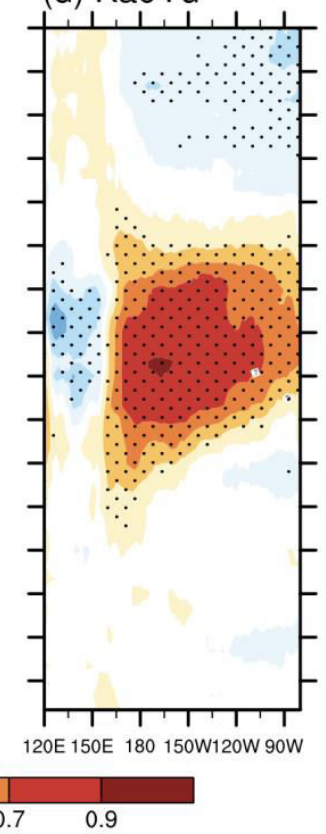

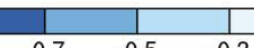

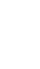




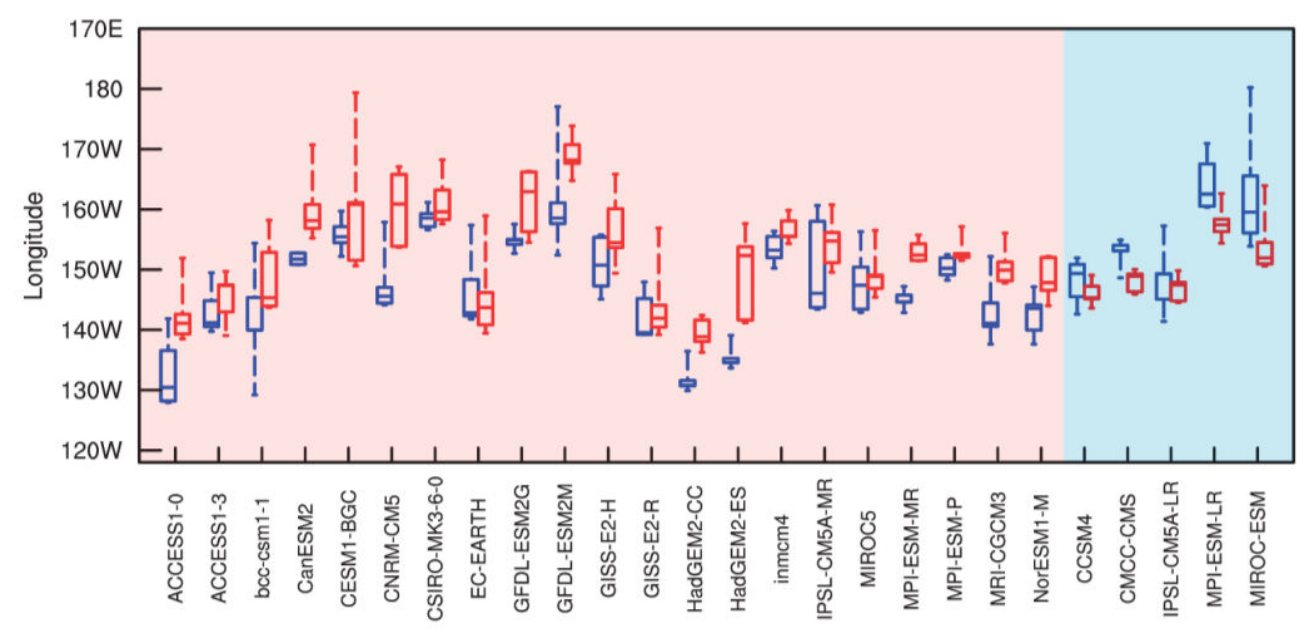

623 Figure 3 Boxplot for the HCI of El Niño derived from the preindustrial simulations of

624 CMIP5. Each model has two boxes: one is blue for the HCI after the CP-cooling-like mode;

625 the other is red but for the HCI after the EP-cooling-like mode. An EP-cooling-like mode (a

626 CP-cooling-like mode) is defined as the negative SSTA in the eastern tropical Pacific (in the

627 central tropical Pacific) less than the SSTA in the central tropical Pacific (in the eastern 628 tropical Pacific).

629 


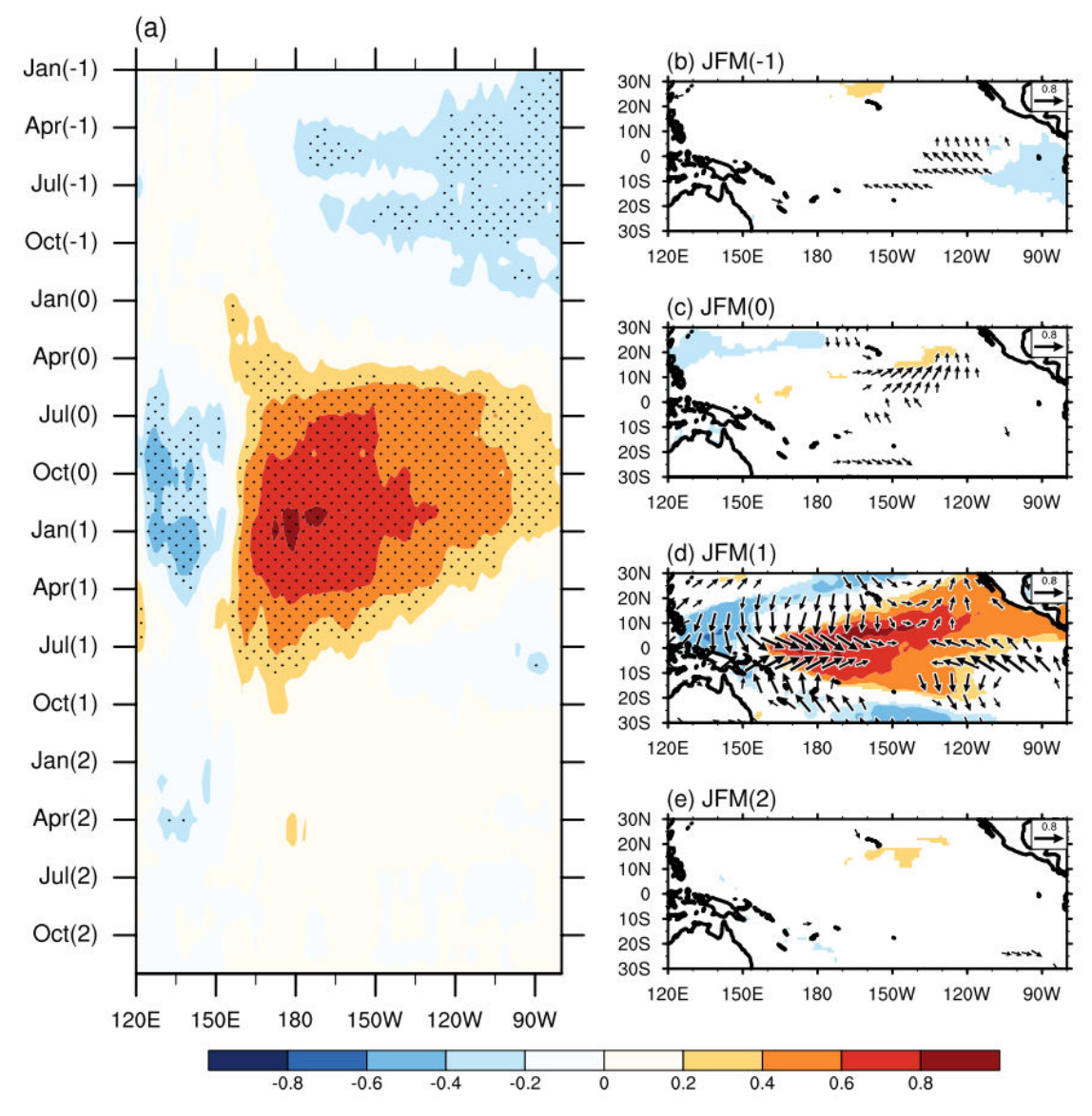

631 Figure 4 Correlations between the wintertime (i.e., December-January-February) CPI and

632 the tropical SST and surface wind anomalies. (a) Correlation of the wintertime CPI with

633 tropical SST; and (b-e) horizontal distributions of the correlations of the wintertime CPI with

634 the 3-month (i.e., January-February-March) averaged wind (vector) and SST (shaded). The

635 CPI is the Modoki index proposed by Ashok et al. (2007). The bracketed number "0" denotes

636 the correlation of the wintertime CPI with the SST and wind anomalies in the same year; and

637 " $-1 "$, " 1 ", and "2" indicate the correlation of the wintertime CPI with the SST and wind 638 anomalies in the last year, next year, and the year after next, respectively. The correlations 639 above $99 \%$ confidence are dotted in (a), and only correlations above $99 \%$ confidence are 640 shown in (b-e). 


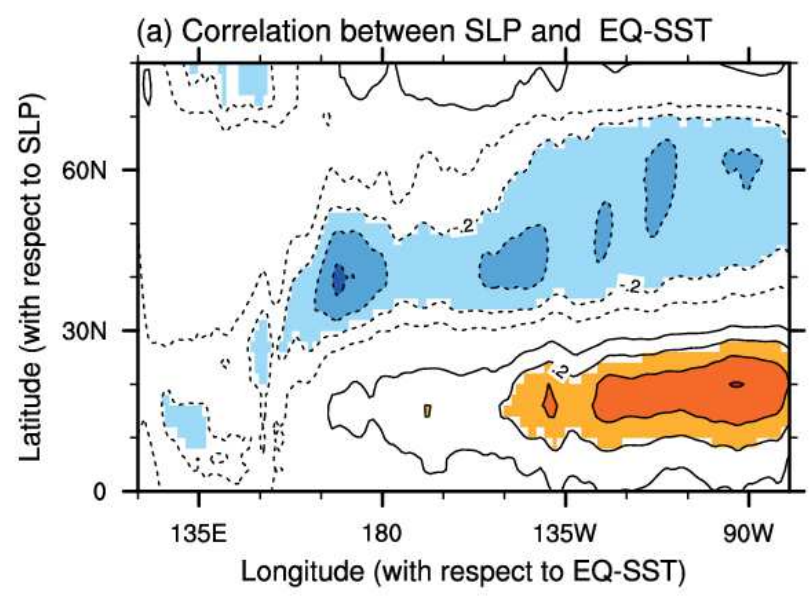

(b) SLP related to the previous EP-SST

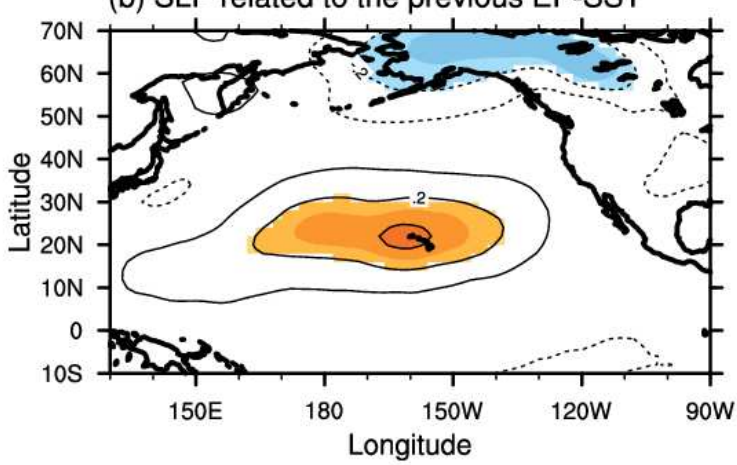

(c) SLP related to the previous Nino3.4

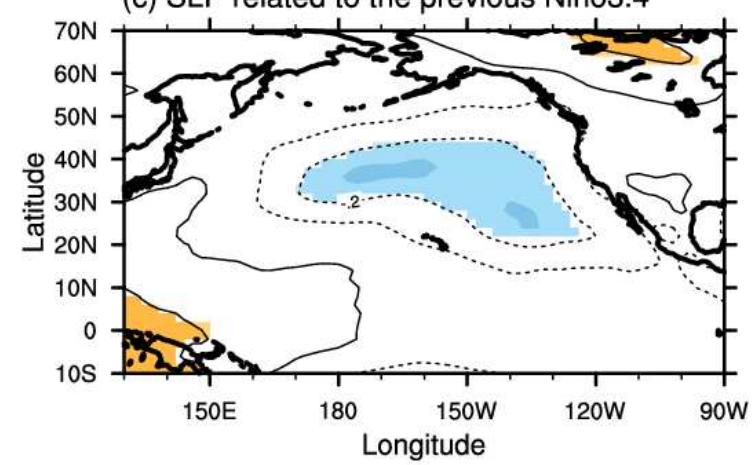

643 Figure 5 (a) Cross-correlations between the April-May-June averaged SSTAs along the

644 equatorial Pacific and the February-March-April averaged SLP anomalies over the North

645 Pacific one year later; Correlation maps between the SLP anomalies and (b) the SSTAs in the 646 eastern tropical Pacific (EP-SST) that are filtered the linear effect of the Niño3.4 indices and

647 (c) Niño3.4 indices that are filtered the linear effect of the EP-SST. In Figure a, the SSTAs 648 are meridionally averaged between $5^{\circ} \mathrm{S}$ and $5^{\circ} \mathrm{N}$, and the SLP anomalies are zonally averaged 649 between $170^{\circ} \mathrm{W}$ and $160^{\circ} \mathrm{W}$. Correlations above $95 \%$ confidence are shaded.

650

651

652 
(a) EP cooling in JFM
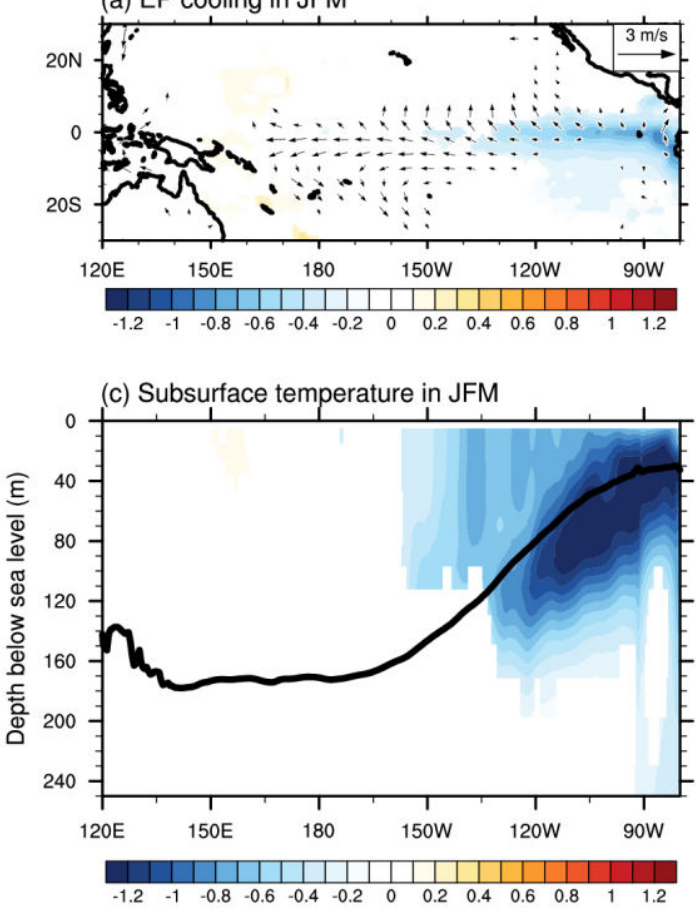

(b) Sea level anomalies in SON
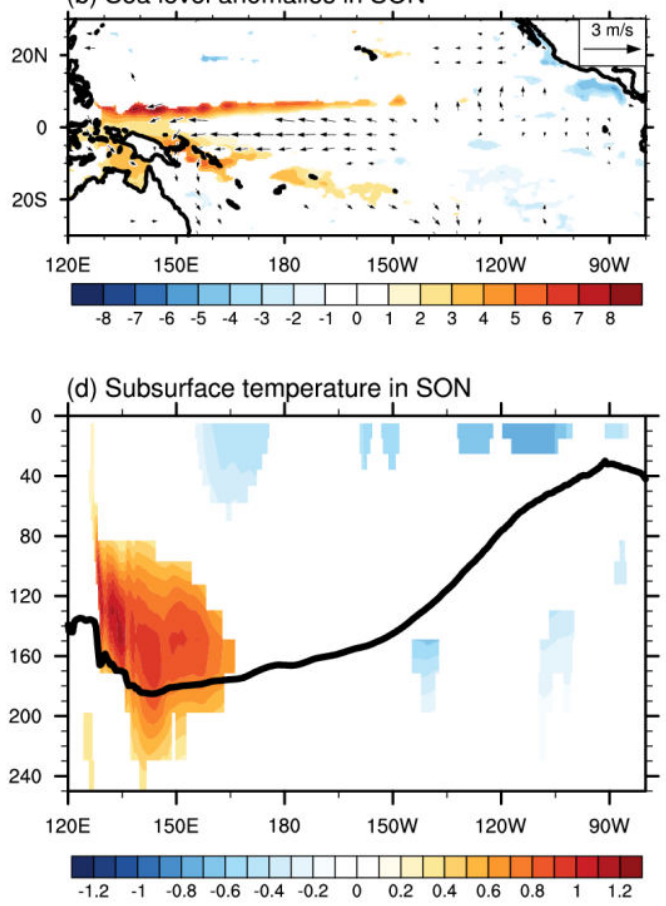

Figure 6 Composites of (a) EP-cooling-related winter (JFM) SST and wind anomalies,

657 (b) EP-cooling-induced SL anomalies in September-October-November, (c) EP-cooling-

658 related subsurface temperature anomalies in winter and (d) EP-cooling-induced subsurface

659 temperature anomalies in September-October-November. Here, the EP-cooling mode is

660 determined as the SSTAs in the eastern tropical Pacific (averaged over the region

$661110^{\circ} \mathrm{W} \sim 80^{\circ} \mathrm{W}, 5^{\circ} \mathrm{S} \sim 5^{\circ} \mathrm{N}$ ) during winter and spring (i.e., January-June) less than -0.7 its

662 standard deviation and especially less than those in the central tropical Pacific. The year of

663 EP-cooling mode is therefore identified and a composite analysis is finally made for the

664 climate variables as well as the following year climate states. The results that pass $90 \%$

665 confidence level are shown. 

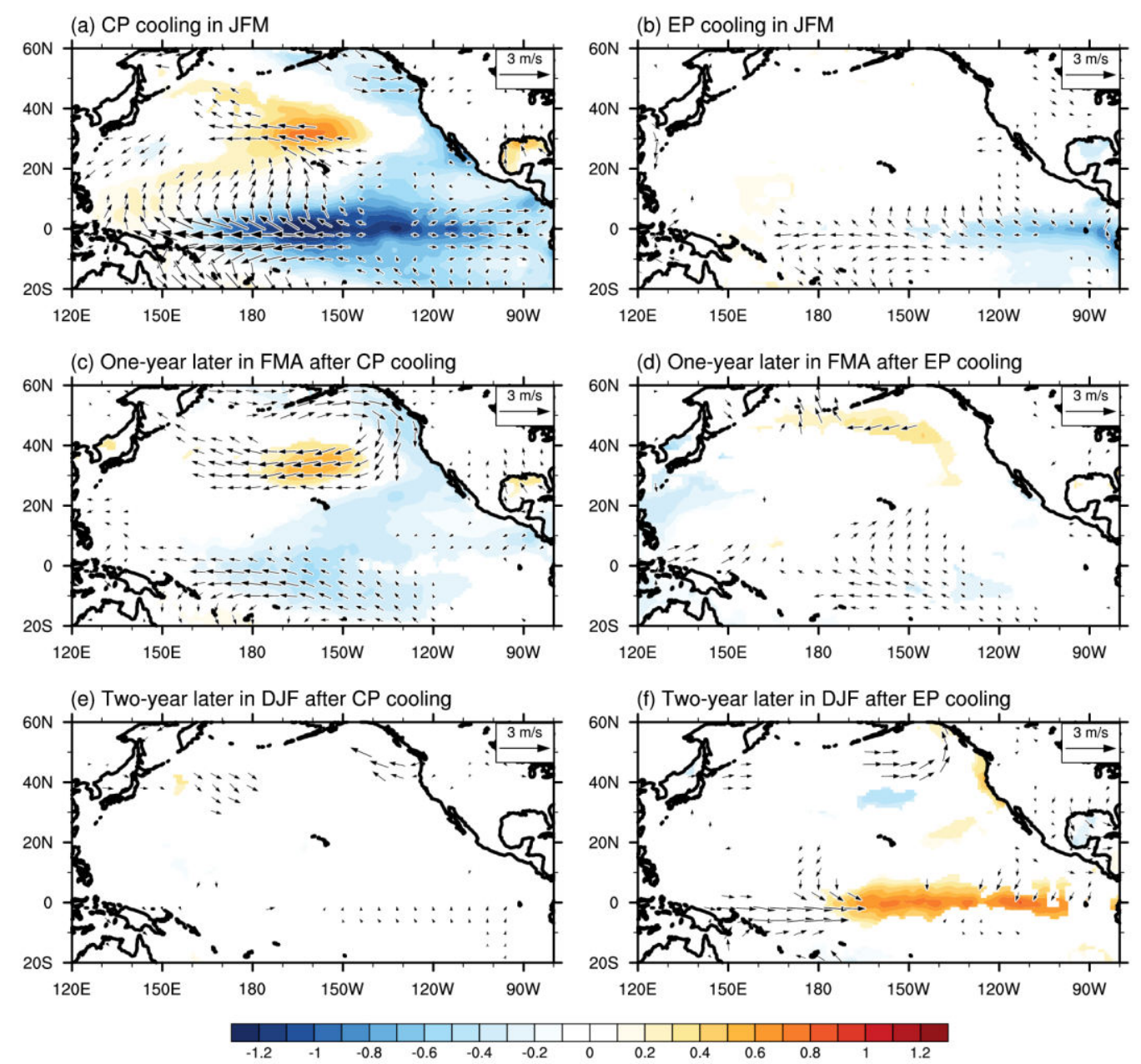

668

Figure 7 Composites of the SSTA and surface wind anomalies that are induced by the

669 CP-cooling and EP-cooling modes. The composite for CP-cooling mode is made when the

670 SSTAs in the central tropical Pacific (averaged over the region $175^{\circ} \mathrm{W} \sim 110^{\circ} \mathrm{W}, 5^{\circ} \mathrm{S} \sim 5^{\circ} \mathrm{N}$ ) are

671 less than -0.8 its standard deviation during winter and spring and simultaneously lower than

672 the values in the eastern tropical Pacific. Only the results that pass the $90 \%$ confidence level 673 are shown. 

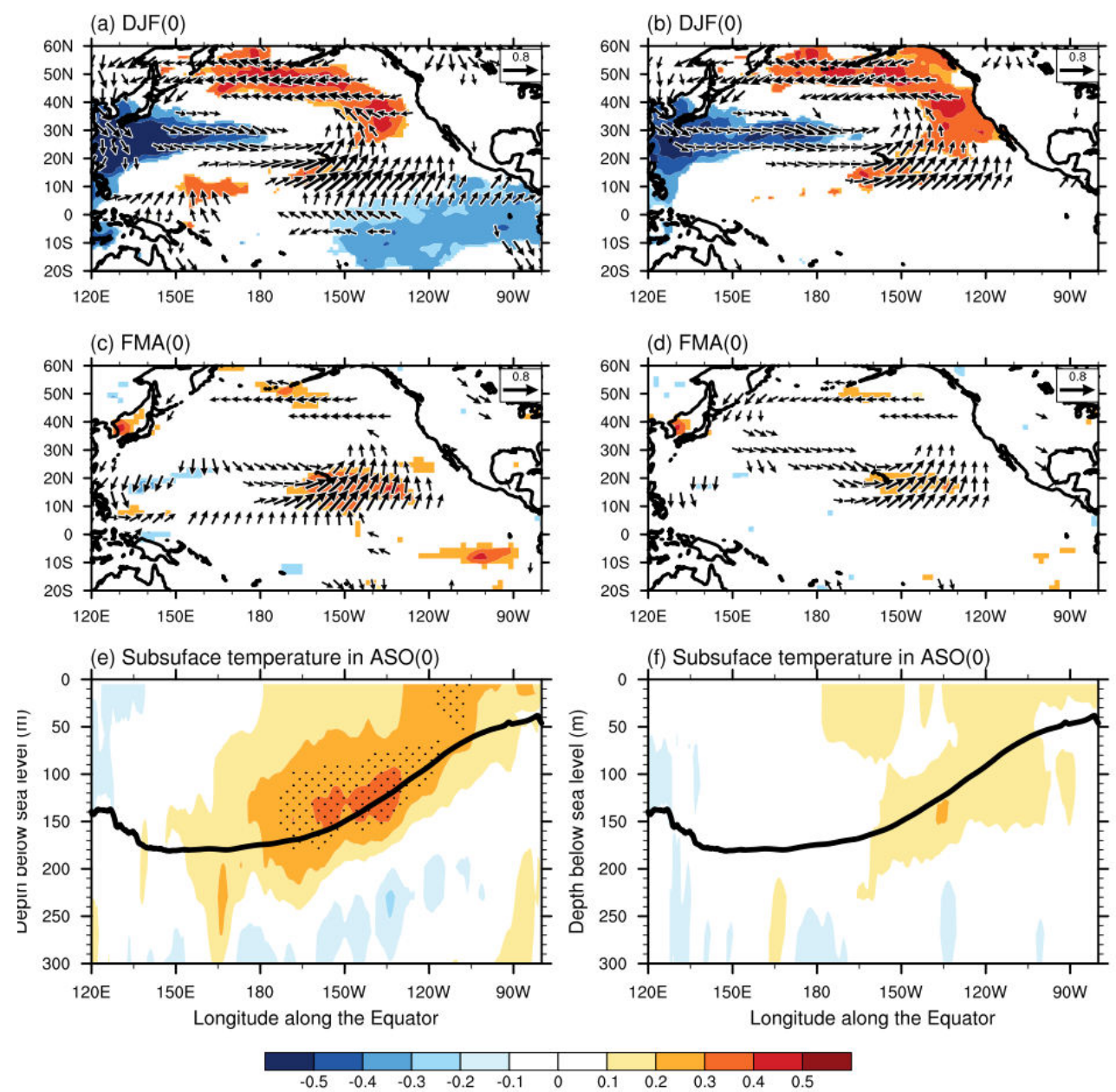

Figure 8 Correlations of the VMI in spring (i.e., February-March-April) with the (a)

677 surface wind (vector) and SSTA (shaded) during December-January-February, (c) surface

678 wind and latent heat flux anomaly (shaded) during February-March-April and (e) subsurface

679 temperature during August-September-October. The right panels (b, $d$ and $f$ ) show the

680 correlation of residual VMI that filters the linear effect of the leading SSTAs in the eastern

681 tropical Pacific. The black curves in (e) and (f) denote the depths of the thermocline along the 682 equator. The correlations pass 95\% confidence are shown in (a)-(d) and dotted in (e) and (f). 
(a) SST anomaly along the equator

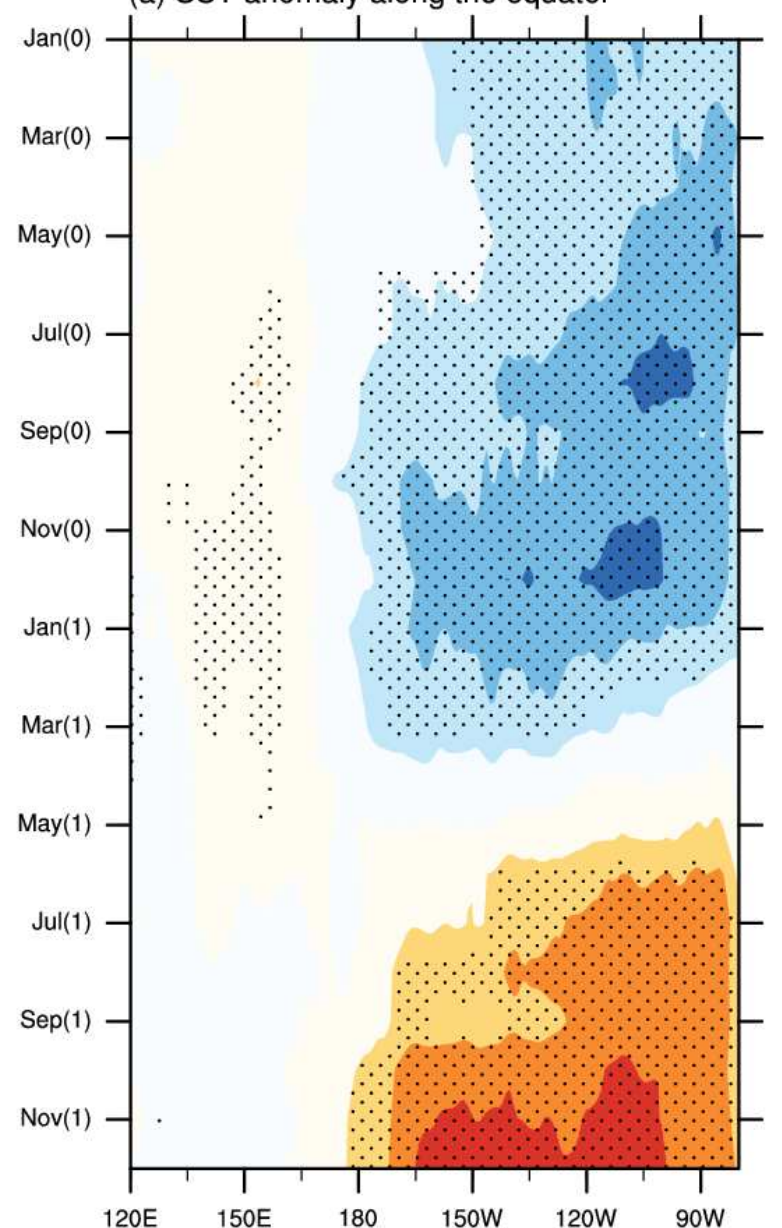

(b) Feb(0)

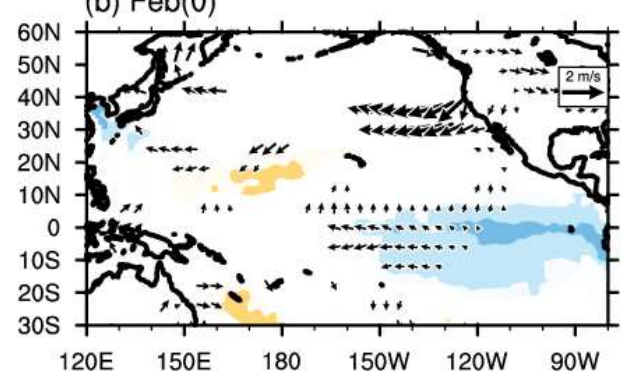

(c) Feb(1)

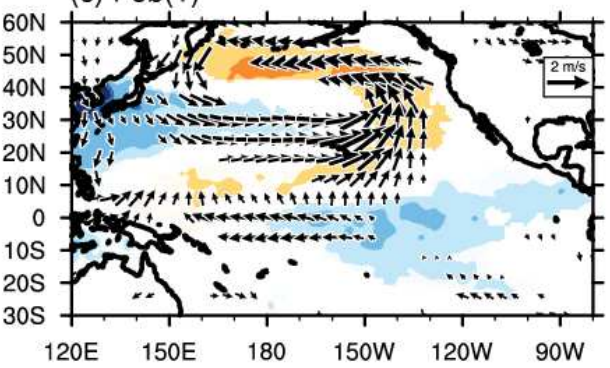

(d) $\operatorname{Dec}(1)$

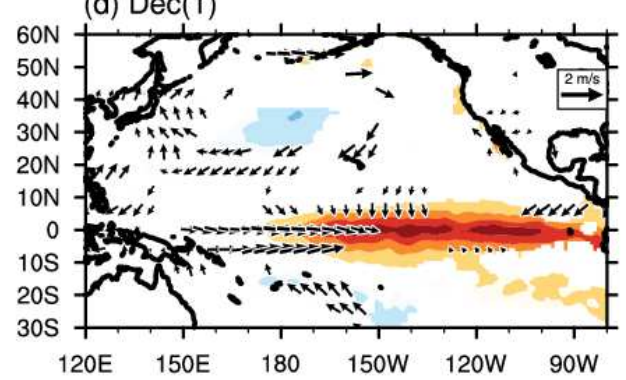

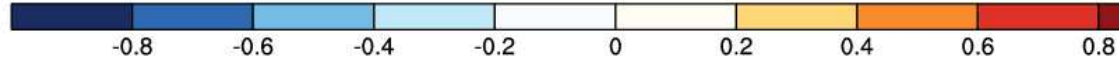

686 Figure 9 Composites of SSTA and wind that are related to the VM and EP-cooling mode.

687 Dots in (a) indicate the composite SSTA pass $90 \%$ confidence. Only composites that pass $68890 \%$ confidence are shown in (b)-(d). 
(a) SST anomaly along the equator

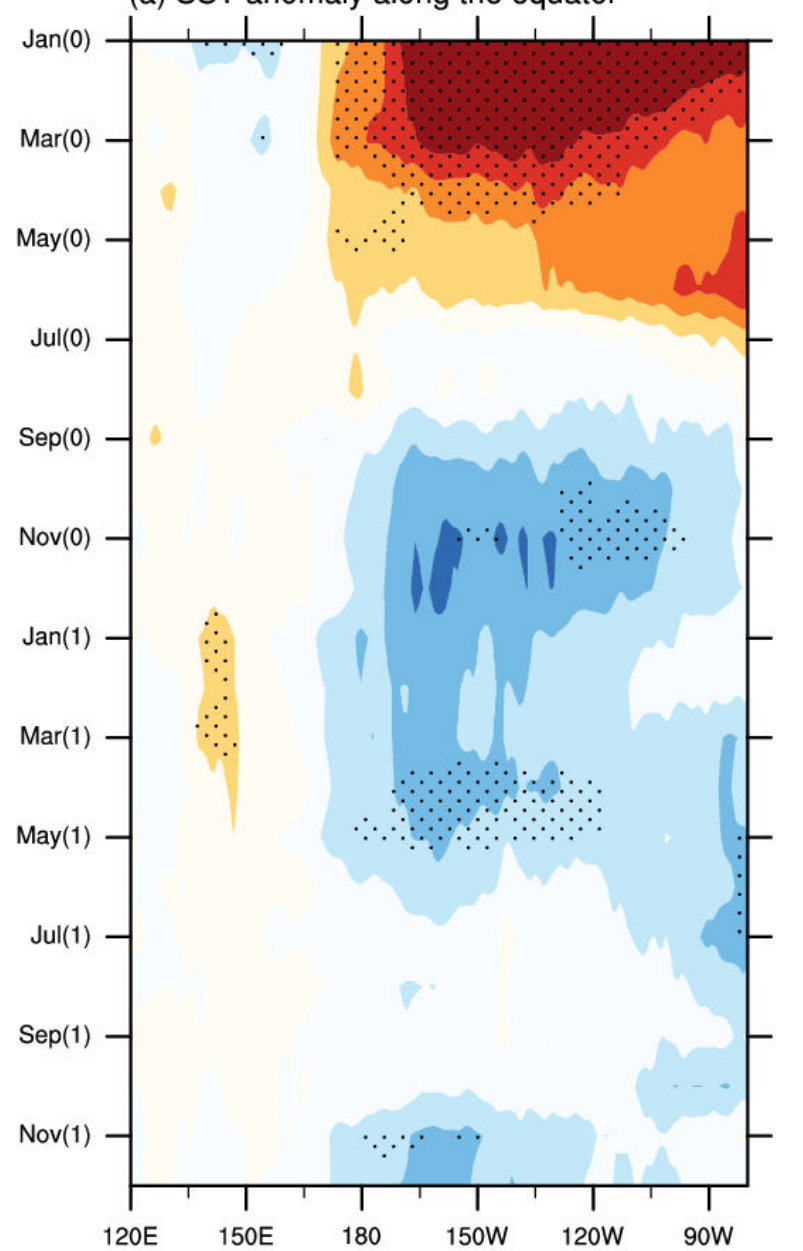

(b) $\mathrm{Feb}(0)$

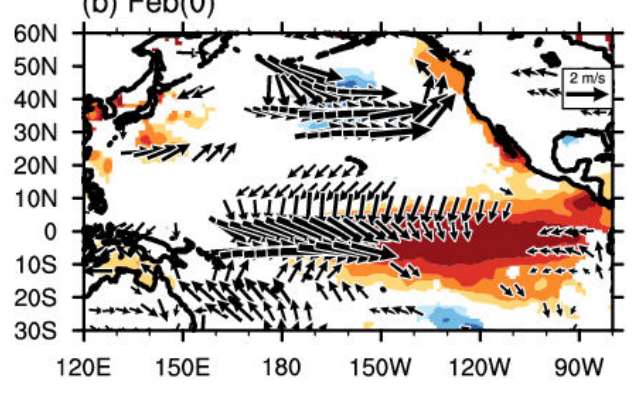

(c) Feb(1)

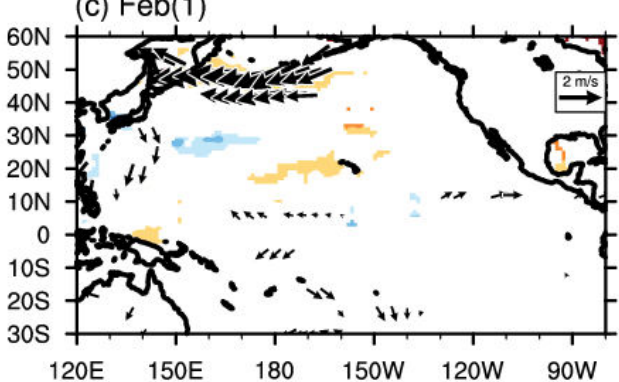

(d) $\operatorname{Dec}(1)$

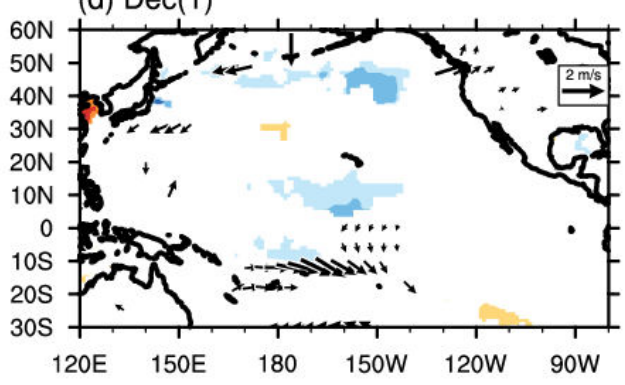

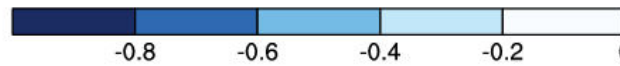

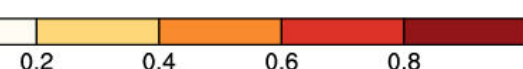

691 Figure 10 Same as in Figure 9, except for those related to VM but unrelated to EP692 cooling.

693

694 

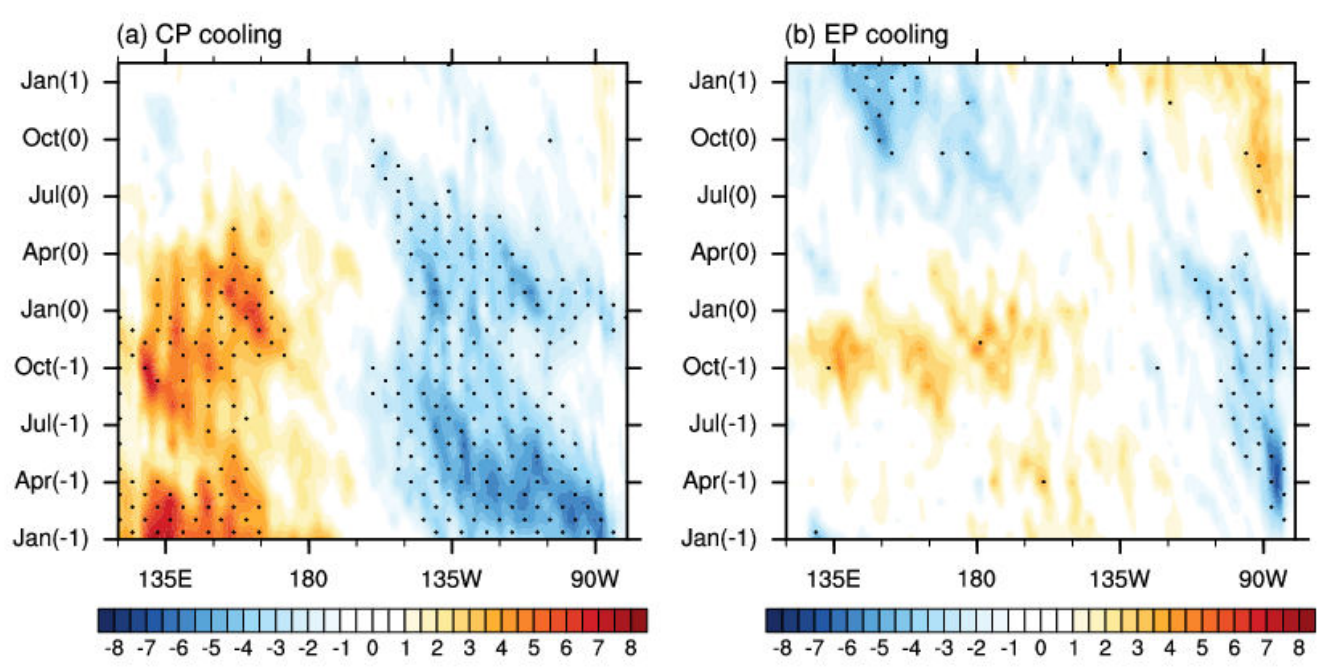

695

696 Figure 11 Evolutions of the SL anomalies off the equator (average meridionally in $6^{\circ} \mathrm{N}$ -

$69712^{\circ} \mathrm{N}$ ) that are induced by the (a) CP-cooling and (b) EP-cooling modes. Dots indicate that 698 the composites of SL anomalies pass the $90 \%$ confidence level. 

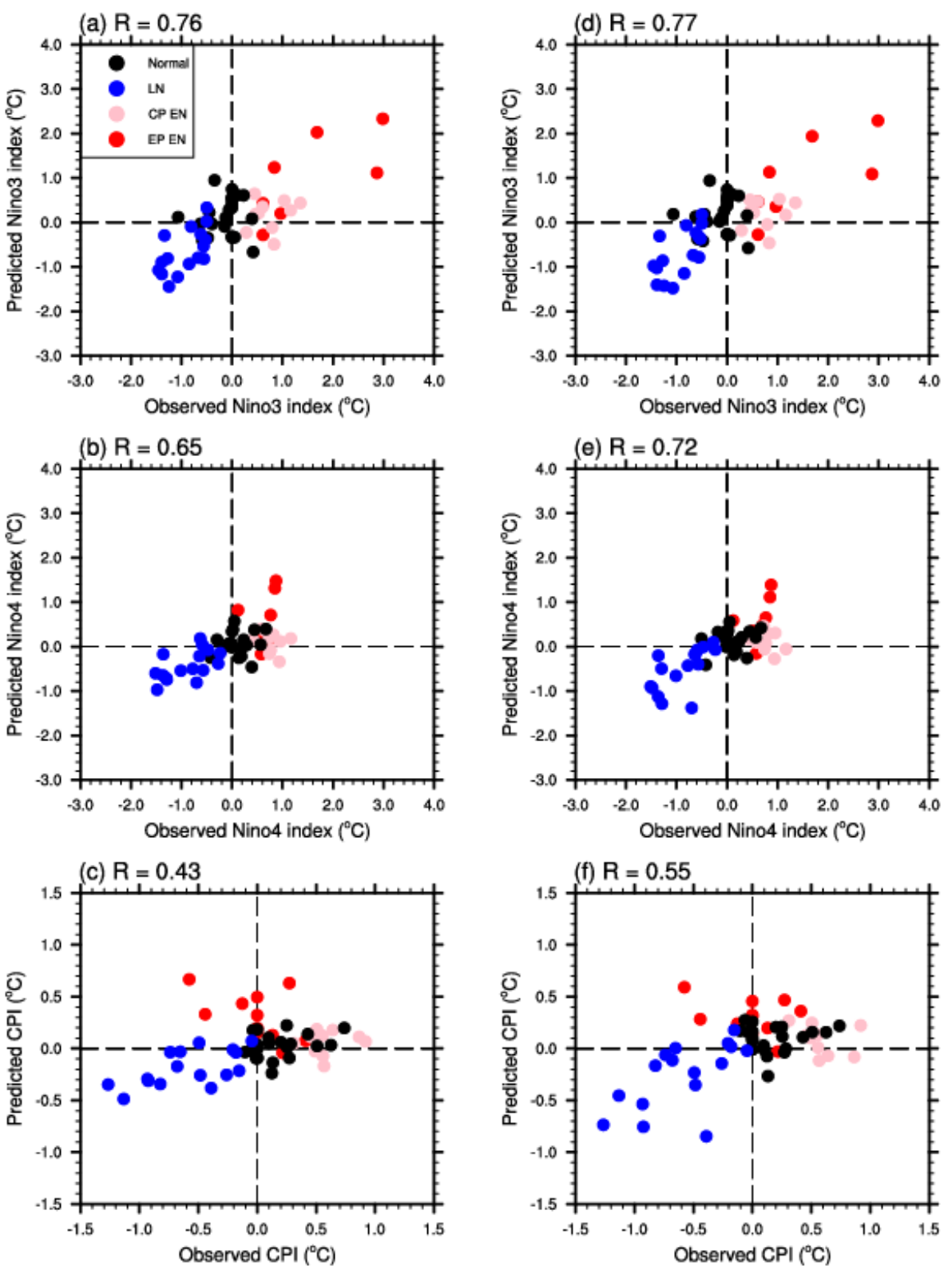

701 Figure 12 Relations between the predicted and observed Niño indices in winter during 702 1960-2010. The left panels are derived from the Model 1 prediction, and the right panels are 703 from the Model 2 prediction. 
(a) CPI: trained during 1960-1985
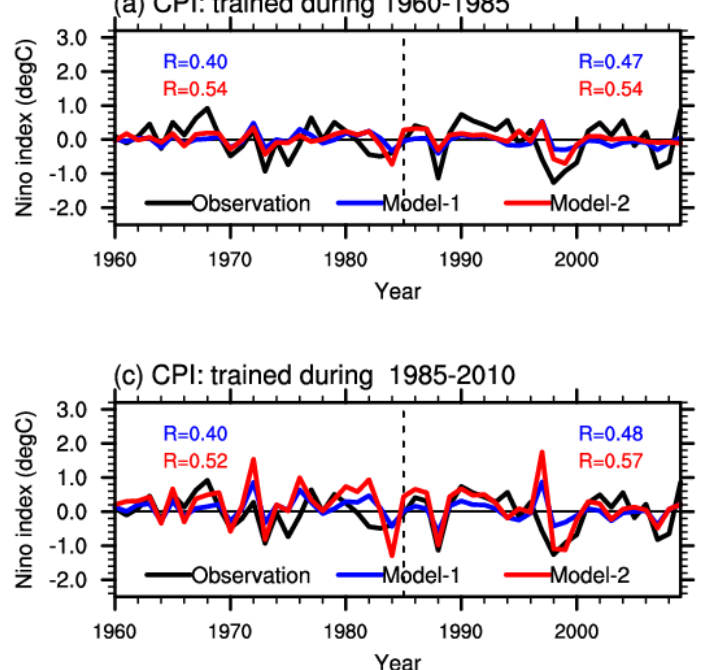

(b) Nino4: trained during 1960-1985
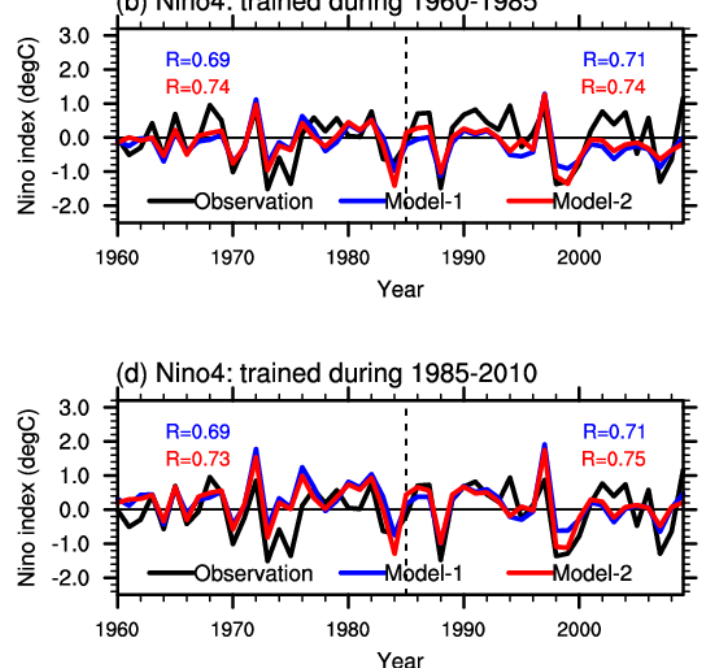

Figure 13 Times series of Niño indices derived from observation and model predictions.

709 (a) and (b) are from the predictions by the models that are trained during 1960-1985, (c) and

710 (d) are from the models that are trained during 1985-2010. The correlations between

711 predicted and observed Niño indices during the period 1960-1985 and the period 1985-2010

712 are listed over the left and right part of each panel, respectively. The black curves are the

713 observation. The red and blue curves are prediction results from Model 1 and Model 2,

714 respectively. The CPI, i.e., the CP-El Niño index, is obtained by the method proposed by

715 Ashok et al. (2007). 


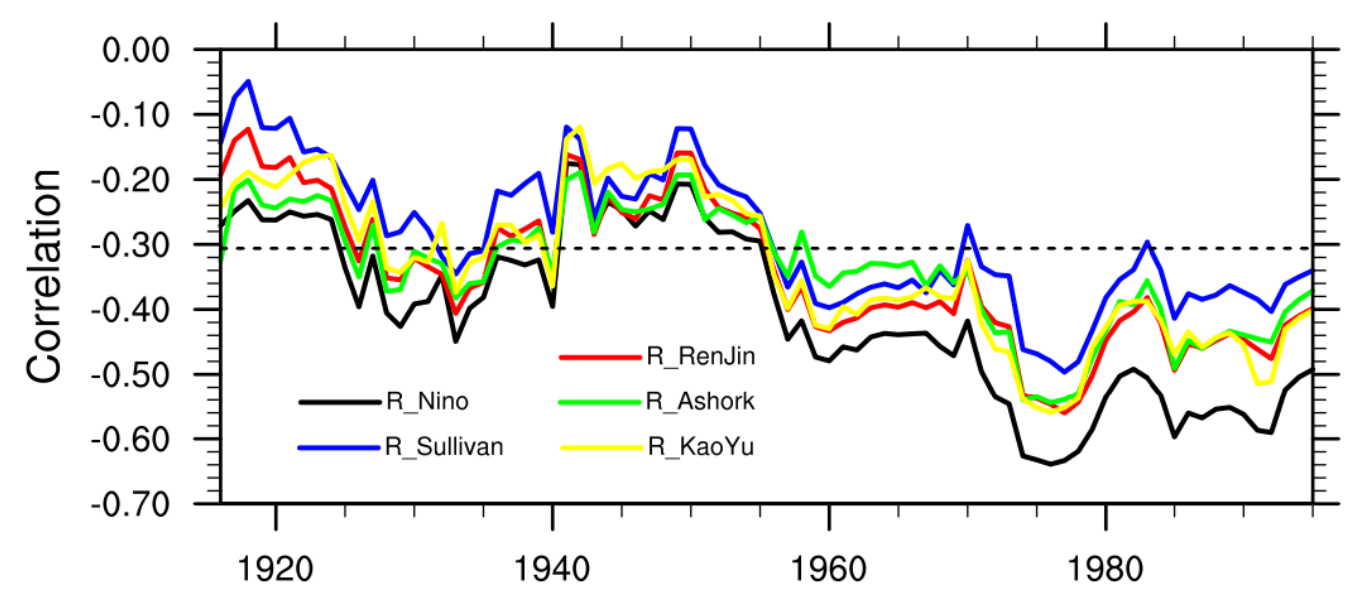

719 Figure 14 The decadal variability of correlations between wintertime CPI and leading

720 EP-SST under a 30-year sliding window. Each colored curve is calculated by using the CPIs

721 that proposed by the corresponding researchers.

722

723 